Document downloaded from:

http://hdl.handle.net/10251/144314

This paper must be cited as:

Requena-Peris, R.; Jiménez Quero, A.; Vargas, M.; Moriana Torró, R.; Chiralt A.; Vilaplana Domingo, FJ. (18-0). Integral Fractionation of Rice Husks into Bioactive Arabinoxylans, Cellulose Nanocrystals, and Silica Particles. ACS Sustainable Chemistry \& Engineering. 7(6):6275-6286. https://doi.org/10.1021/acssuschemeng.8b06692

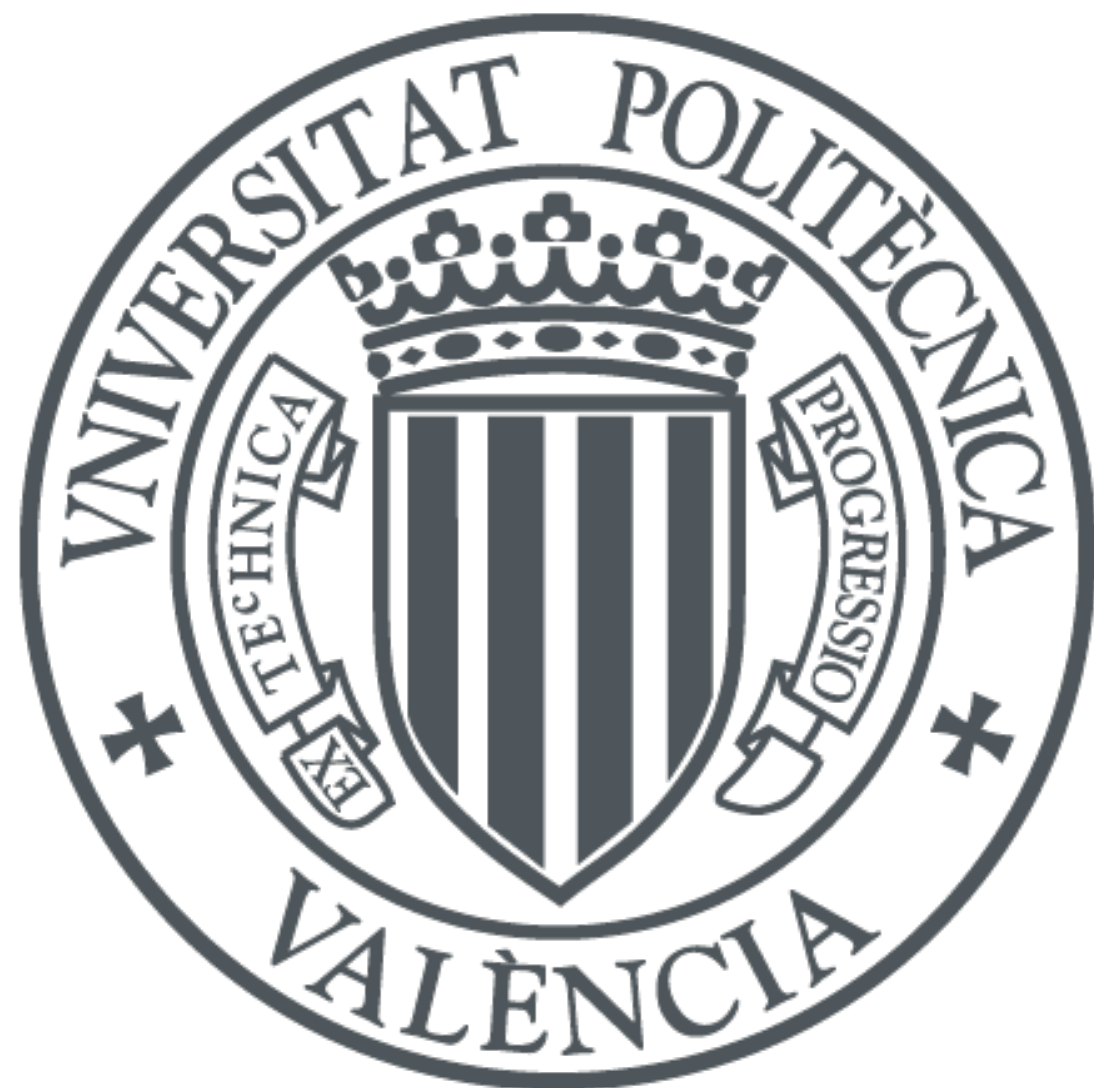

The final publication is available at

https://doi.org/10.1021/acssuschemeng.8b06692

Copyright American Chemical Society

Additional Information

This document is the Accepted Manuscript version of a Published Work that appeared in final form in ACS Sustainable Chemistry \& Engineering, copyright (C American Chemical Society after peer review and technical editing by the publisher. To access the final edited and published work see https://doi.org/10.1021/acssuschemeng.8b06692 


\section{Integral fractionation of rice husks into bioactive arabinoxylans, cellulose nanocrystals and silica particles}

Raquel Requena $^{\dagger}$; Amparo Jiménez-Quero ${ }^{\star}$; María Vargas ${ }^{\dagger}$; Rosana Moriana ${ }^{\S, \Delta * ;}$ Amparo Chiralt ${ }^{\dagger *}$; Francisco Vilaplana ${ }^{\ddagger * * *}$

${ }^{\dagger}$ Institute of Food Engineering for Development, Universitat Politècnica de València, Valencia, Spain.

$¥$ Division of Glycoscience, Department of Chemistry, School of Engineering Sciences in Chemistry, Biotechnology and Health, KTH Royal Institute of Technology, Stockholm, Sweden.

${ }^{\S}$ Division of Polymeric Materials, Department of Fibre and Polymer Technology, School of Engineering Sciences in Chemistry, Biotechnology and Health, KTH Royal Institute of Technology, Stockholm, Sweden.

${ }^{\triangle}$ Department of Molecular Sciences, SLU Swedish University of Agricultural Sciences, Uppsala, Sweden.

\#Wallenberg Wood Science Center, KTH Royal Institute of Technology, Stockholm, Sweden.

\section{*Corresponding authors:}

Rosana Moriana (

Amparo Chiralt (dchiralt@tal.upv.es)

Francisco Vilaplana (담vila@kth.se) 


\begin{abstract}
Rice husk is an important agricultural by-product that has not been exploited yet to full capacity for advanced applications. The feasibility of obtaining high-value products such as bioactive hemicelluloses and cellulose nanocrystals (CNCs) from rice husk is here demonstrated in a cascade biorefinery process using subcritical water extraction (SWE) prior to bleaching and acid hydrolysis, and compared to traditional alkali pretreatments. The proposed SWE process enables the isolation of bioactive arabinoxylans with phenolic acid moieties, thus preserving their antioxidant and antibacterial properties that are lost during alkaline conditions. Additionally, SWE can be combined with subsequent bleaching and acid hydrolysis to obtain CNCs with large aspect ratio, high crystallinity and thermal stability. The hydrothermal process also enables the recovery of silica particles that are lost during the alkali step, but can be recovered after the isolation of the CNCs. Our biorefinery strategy results in the integral valorization of rice husk into their molecular components (bioactive arabinoxylans, cellulose nanocrystals and silica particles), which can be used as additives for food applications and as reinforcing agents in biocomposite materials, respectively.
\end{abstract}

Keywords: rice husk; subcritical water extraction; xylans; cellulose nanocrystals; biorefinery 


\section{Introduction}

2 Rice constitutes a global food crop currently grown in over a hundred countries, producing over 715 million Tn of paddy rice annually. On average, paddy rice generates $25 \%$ husk, $10 \%$ bran and germ, and $65 \%$ white rice ${ }^{1}$. Therefore, the rice milling industry generates annually a vast volume of rice husk by-products, which can be considered as a valuable renewable resource in the current context of circular and biobased economy. Rice husk is mainly composed of cellulose (40\%), hemicellulose (30\%), lignin $(10 \%)$ and silica $(20 \%){ }^{2}$ Several strategies have been proposed for the valorization of rice husk as such, including the use as renewable fuel due to its high calorific power, ${ }^{3-4}$ as partial replacement for building materials, ${ }^{5}$ and as a filler in bioplastic materials ${ }^{6-8}$. However, such bulk applications do not exploit the full potential of the inherent phytochemical and lignocellulosic components present in rice husk for high value products. ${ }^{9}$

The overarching goal of any biorefinery approach should aim for a near-complete utilization of the inherent biomass components, generating multiple products in a cascade manner. Given the high cellulose content of rice husk, these fibres can be used as a cheap raw material for developing cellulose-based products. In this context, cellulose nanocrystals (CNCs) consisting of highly crystalline rod-shaped cellulose regions, show great potential as reinforcing agents for different composites. ${ }^{10}$ Other fields of potential applications for the CNCs include barrier and antimicrobial films, flexible displays, biomedical implants, pharmaceuticals, drug delivery, fibres and textiles, templates for electronic components, separation membranes, batteries, supercapacitors, and many others. ${ }^{11}$

The isolation of CNC from plant biomass occurs in two stages, an initial pre-treatment of the raw material to isolate the cellulosic fibres, resulting in the complete or partial removal of matrix materials such as hemicelluloses and lignin, followed by a controlled chemical 
treatment, in order to remove the amorphous regions of the cellulose polymer. ${ }^{12}$ The exploitation of the high hemicellulose fraction of $\mathrm{RH}$, which is mainly made up of substituted arabinoxylans, also offers interesting possibilities. Xylans have large potential as natural substitutes for synthetic texturizing agents and antioxidants for food, cosmetics and biomedical applications due to their rheological properties combined with their antioxidant and/or antimicrobial activity. ${ }^{13}$ The most common process applied to extract the hemicellulose fractions from plant by-products is based on severe alkaline treatments to disrupt the crosslinked and recalcitrant lignocellulosic biomass architecture. ${ }^{14-15}$ Nonetheless, these conditions promote the removal of the native chain-linked acetyl and phenolic compounds, which leads to a loss in the hemicelluloses' functionality. ${ }^{13}$ Subcritical water extraction (SWE), also refereed in the literature as pressurized hot-water extraction (PHWE) and superheated water extraction, emerges as a promising green technique for the isolation of hemicellulose fractions with preserved molecular functionalities and high molecular weight. ${ }^{13}$ Compared to conventional treatments (acid, alkali and enzymatic hydrolysis), the use of water under subcritical conditions (temperatures and pressures below the critical point to maintain liquid state) has numerous advantages, since it is scalable, uses non-toxic solvents, does not require pre-treatments, is faster, and presents a lower degree of sugar degradation. ${ }^{16-17}$

In this study, a bioprocess towards the integral fractionation of rice husk is proposed, using subcritical water as an alternative to alkaline extraction to release matrix polysaccharides, prior to bleaching and acid hydrolysis to obtain cellulose nanocrystals (Figure 1). The yields, composition and properties of the obtained fractions were compared to those found using the common alkali process. The overall process enables the simultaneous extraction of polymeric hemicelluloses (xylans) with bioactive properties, and the isolation of cellulose nanocrystals and silica particles, useful as reinforcing agents. 
51 The rice husk was kindly provided by Dacsa Group (Valencia, Spain), dried at room temperature for one week and milled with a Wiley Mill Acm 82302 (Acmas Technocracy Pvt. Ltd, Germany) to a 20 mesh.

\section{Bioprocess design}

Two parallel cascade processes have been considered for the integral valorization of the fractions present in rice husk: (i) an "alkaline process" consisting of an initial treatment under alkaline conditions, and subsequent bleaching and acid hydrolysis steps, and (ii) an alternative "hydrothermal process", where subcritical water extraction (SWE) replaces the traditional alkaline treatment, followed by bleaching and acid hydrolysis (Figure 1).

\section{Extraction of arabinoxylans from rice husks}

Subcritical water extraction (SWE) of the milled rice husk samples was performed using a Accelerated Solvent Extraction equipment (Dionex ${ }^{\mathrm{TM}}$ ASETM 350 , USA) at $160{ }^{\circ} \mathrm{C}$ and $\mathrm{pH} 7$ on the basis of the optimized xylan yields reported for wheat bran. ${ }^{13}$ Extractions were performed sequentially using $2 \mathrm{~g}$ of milled sample with sequential extraction cycles of 5,10 , 15 and 30 min, resulting in four extracts (E-H5, E-H15, E-H30 and E-H60) and an insoluble fraction $(\mathrm{RH}-\mathrm{H})$. The extracts and residue were freeze-dried for $72 \mathrm{~h}$ for further analyses.

Alkaline extraction from rice husk was performed in triplicates following the procedure described by Moriana et al. ${ }^{18}$ In brief, milled rice husk (4 wt $\%$ ) was successively treated three times with a $\mathrm{NaOH}$ solution $(4.5 \% \mathrm{w} / \mathrm{v})$ at $80{ }^{\circ} \mathrm{C}$ for $2 \mathrm{~h}$ under mechanical stirring, filtered and washed. The alkali extracts (E-A1, E-A2, E-A3) obtained after each alkali treatment and the insoluble fraction (RH-A) were dialyzed for $48 \mathrm{~h}$ using a $3.5 \mathrm{kDa}$ membrane (Spectra/Por 3 Dialysis Membrane, SpectrumLabs, The Netherlands) and freeze-dried for further analyses. 
The insoluble fractions coming from the SWE $(\mathrm{RH}-\mathrm{H})$ and the alkaline $(\mathrm{RH}-\mathrm{A})$ processes were subjected to five consecutive bleaching treatments in order to remove the lignin and residual hemicellulose following the methodology previously described. ${ }^{19}$ Dried residues (4 wt\%) were treated with bleaching solutions consisting of equal parts of acetate buffer ( $2 \mathrm{M}$, $\mathrm{pH} 4.8)$, aqueous chlorite $(1.7 \% \mathrm{w} / \mathrm{v})$ and water, at $80{ }^{\circ} \mathrm{C}$ for $4 \mathrm{~h}$ under mechanical stirring. Two bleached samples were thus obtained, those coming from the RH-A sample (RH-A-B) and those coming from the $\mathrm{RH}-\mathrm{H}(\mathrm{RH}-\mathrm{H}-\mathrm{B})$.

The acid hydrolysis was conducted after the bleaching treatment on both fibres (RH-A-B and RH-H-B) using the conditions described by Moriana et al. ${ }^{18}$ The bleached residues (4 wt $\%$ ) were treated with $65 \mathrm{wt} \%$ sulphuric acid (preheated) at $45{ }^{\circ} \mathrm{C}$ for $40 \mathrm{~min}$ under continuous stirring. The hydrolysed material was washed with water and centrifuged at $25000 \mathrm{~g}$ for 20 min (Rotofix 32A Hettich Zentrifugen, Germany). The residue was water suspended and dialysed against distilled water for several days, using a 6-8 KDa membrane (Spectra/Por 1, SpectrumLabs, Breda, The Netherlands). The resulting suspensions were sonicated for $10 \mathrm{~min}$ while cooling in an ice bath, centrifuged at $4500 \mathrm{rpm}$ for $10 \mathrm{~min}$ to remove the higher particles and kept at $4{ }^{\circ} \mathrm{C}$ for further analyses.

\section{Characterization of the alkali and SWE soluble hemicellulosic extracts}

Carbohydrate composition. Methanolysis with $\mathrm{HCl}$ in methanol $(2 \mathrm{M})$ was performed on the extracts $\left(1 \mathrm{mg}\right.$ of freeze-dried material) in triplicates at $100{ }^{\circ} \mathrm{C}$ for $5 \mathrm{~h}$, followed by hydrolysis with TFA $2 \mathrm{M}$ at $120{ }^{\circ} \mathrm{C}$ for $1 \mathrm{~h}$. The monosaccharides were separated and quantified by HPAEC-PAD on an ICS3000 system (Dionex, Sunnyvale, CA) using a Dionex CarboPac PA1 column at $30{ }^{\circ} \mathrm{C}$ at a flow rate of $1 \mathrm{~mL} \mathrm{~min}^{-1}$. Two different gradients were applied for the analysis of neutral sugars (fucose, arabinose, rhamnose, galactose, glucose, xylose, mannose), and uronic acids (galacturonic and glucuronic acid), as previously reported..$^{20}$ 
Hydroxycinnamic acid quantification. The hydroxycinnamic acid profile was determined as described by Comino et al. ${ }^{21}$ In brief, $5 \mathrm{mg}$ of dry samples (in triplicates) were saponified with $500 \mu \mathrm{l}$ of $2 \mathrm{M} \mathrm{NaOH}$ overnight at room temperature, acidified to $\mathrm{pH} 3.0(12 \mathrm{M} \mathrm{HCl})$, extracted with ethyl acetate, and dried. The dried samples were then silylated with 1(trimethylsilyl)-imidazole-pyridine $\left(100^{\circ} \mathrm{C}, 5 \mathrm{~min}\right)$ and resuspended in acetone before injection to gas chromatography with electron impact mass spectrometry (GC-MS, HP-6890 GC coupled to an HP-5973, Agilent Technologies, Santa Clara, CA) using a CP Sil 5CB column (Agilent Technologies, Santa Clara, CA). ${ }^{13}$

Glycosidic linkage analysis. Glycosidic linkage analysis of the hemicellulose extracts was performed in triplicate by methylation with methyl iodide in dimethyl sulfoxide (DMSO) with excess of $\mathrm{NaOH}$ using the conditions reported by Ciucanu \& Kerek. ${ }^{22}$ The methylated polysaccharides were hydrolyzed ( $2 \mathrm{M}$ trifluoroacetic acid, $\left.121^{\circ} \mathrm{C}, 3 \mathrm{~h}\right)$ and further derivatized by reduction with $\mathrm{NaBH}_{4}$ and acetylation with acetic anhydride and pyridine. The permethylated alditol acetates (PMAAs) were analysed by GC-MS on a SP-2380 capillary column (Sigma-Aldrich), as previously reported. ${ }^{23}$

Molar mass distributions. The molar mass distributions of the different hemicellulose extracts were analysed by size-exclusion chromatography (SECcurity 1260, Polymer Standard Services, Mainz, Germany) coupled to a refractive index detector (SECcurity 1260, Polymer Standard Services, Mainz, Germany) in DMSO with $0.5 \% \mathrm{w} / \mathrm{w} \mathrm{LiBr}$ at $60^{\circ} \mathrm{C}$. Calibration was performed by injection of pullulan standards of known molar masses (Polymer Standard Services, Mainz, Germany). ${ }^{23}$

Radical scavenging activity of the extracts. The scavenging activity of the hemicellulosic extracts was measured in triplicate by using the 2,2-Diphenyl-1-pikryl-hydrazyl (DPPH) reduction method. ${ }^{24}$ These measurements were carried out for the SWE and alkali extracts 
with the highest xylan contents, E-H60 and E-A3, respectively. Briefly, aliquots of the properly diluted samples were mixed with a methanol solution of DPPH $\left(0.0255 \mathrm{~g} \mathrm{~L}^{-1}\right)$ at a final ratio ranging from $0.025: 1$ to $0.3: 1$. The absorbance of the resulting solutions was measured at $515 \mathrm{~nm}$ every $15 \mathrm{~min}$, until the reaction reached the steady state, using a spectrophotometer (ThermoScientific spectrophotometer Evolution $201 \mathrm{UV}$-vis). The DPPH concentration $(\mathrm{mM})$ was calculated from the calibration curve, whereas the percentage of remaining $\mathrm{DPPH}^{*}\left(\% \mathrm{DPPH}^{-}{ }^{-}\right.$) was calculated from the concentration of $\mathrm{DPPH}^{\cdot}$ at steady state and the concentration at the beginning of the reaction. The parameter EC50 was determined by plotting the $\% \mathrm{DPPH}_{\text {rem }}$ versus the mass ratio of extract to $\mathrm{DPPH}^{\cdot}$ (mg extract/mg DPPH), which indicates the amount of extract required to reduce the initial concentration of $\mathrm{DPPH}^{\cdot}$ to $50 \%$ once the stability of the reaction was reached. ${ }^{25}$

Antibacterial activity of the extracts. A MTT colorimetric assay was carried out in duplicate using a 96-well microtiter plate design, in order to study the antimicrobial activity of the hemicellulosic SWE and alkali extracts with the highest xylan contents. Diluted solutions (150 to $10 \mathrm{mg}$ extract/mL) were prepared from the freeze-dried extracts using Tryptone Soy Broth (TSB) medium. Aliquots of $100 \mu \mathrm{l}$ of each dilution were placed in their corresponding wells and the plates were inoculated with $100 \mu 1$ of bacterial suspensions $\left(10^{5} \mathrm{CFU} / \mathrm{mL}\right)$ of $L$. innocua (CECT 910) or E. coli (CETC 101) provided by the Spanish Type Culture Collection (CECT, Universitat de València, Spain). After $24 \mathrm{~h}$ incubation at $37{ }^{\circ} \mathrm{C}, 10 \mu \mathrm{l}$ of MTT reconstituted in Phosfate Buffered Saline PBS $(5 \mathrm{mg} / \mathrm{mL})$ were added to each well and incubated for $4 \mathrm{~h}$ at $37{ }^{\circ} \mathrm{C}$. MTT is a yellow tetrazolium salt, which is reduced to a purple formazan by the dehydrogenases of a live cell. The minimum inhibitory concentrations (MICs) were determined as the lowest concentration of active compound at which no purple colour was observed. 
147 Chemical composition analyses. The dry content of the different samples was measured by using a Mettler Toledo HB43 moisture analyser (Columbus, OH). The Klason lignin of each residue was estimated following the Tappi test method T222 om- $06,{ }^{26}$ while the total amount of soluble extractives in water and ethanol on the raw residue was determined by Soxhlet extraction. ${ }^{27}$ The ash content of the samples was determined by thermogravimetric analysis (TGA) using a Mettler-Toledo 851 (TGA/SDTA) module (Mettler Toledo, Columbus, OH) ${ }^{28}$ The thermogravimetric method consisted of a heating ramp at $50^{\circ} \mathrm{C} \cdot \mathrm{min}^{-1}$ from $25^{\circ} \mathrm{C}$ to a 3 min isothermal stage at $120^{\circ} \mathrm{C}$, followed by a heating ramp until $950^{\circ} \mathrm{C}$ at $100^{\circ} \mathrm{C} \cdot \mathrm{min}^{-1}$ under $\mathrm{O}_{2}$ atmosphere.

The monosaccharide composition was analysed by conventional two-step sulphuric acid hydrolysis $^{29}$. In brief, $4 \mathrm{mg}$ of the freeze-dried sample was pre-hydrolysed at room temperature for $3 \mathrm{~h}$, diluted until a final concentration of $1 \mathrm{M} \mathrm{H}_{2} \mathrm{SO}_{4}$, and then subjected to the second hydrolysis step at $100^{\circ} \mathrm{C}$ for $3 \mathrm{~h}$. The hydrolysed monosaccharides were separated and quantified by HPAEC-PAD on an ICS3000 system (Dionex, Sunnyvale, CA) using a Dionex CarboPac PA1 column at $30^{\circ} \mathrm{C}$ at a flow rate of $1 \mathrm{~mL} \mathrm{~min}^{-1} \cdot{ }^{20}$

Scanning Electron Microscopy (SEM). The surface morphology of the rice husk fibres was analysed using a Tabletop TM-1000 scanning electron microscope (SEM) (Hitachi, Japan) at $15 \mathrm{kV}$. The effect of the different treatments was assessed by comparison of the untreated, SWE, alkali treated, and bleached fibres. No metal coating of the samples was required, due to observation under variable pressure vacuum.

Atomic Force Microscopy (AFM). The morphology of the CNCs was imaged in the dry state with tapping-mode AFM (Multimode V, Bruker, Santa Barbara, CA) ${ }^{19}$ Images in height and phase modes were recorded with an E-scanner in a scan assist mode. RTESP silica cantilevers 
170 (Bruker) having a tip with a radius of $8 \mathrm{~nm}$ and a spring constant of $20-80 \mathrm{~N} \cdot \mathrm{m}^{-1}$ oscillated at

171 its fundamental resonance frequencies between 306 and $366 \mathrm{kHz}$. The distribution of particle

172 lengths and diameters were obtained from printouts of several height mode AFM images,

173 using the section analysis tool of the NanoScope Analysis software (Bruker, version 1.40).

174 The particle diameters were determined considering the height of the CNCs as equivalent to

175 the diameter to eliminate the effect of the tip radius on the width measurements. Over a

176 hundred individual CNCs were randomly selected and measured to determine their average

177 length and diameter.

Fourier Transform Infrared Spectrometry (FTIR) with Attenuated Total Reflection (ATR).

FTIR spectra of the samples were recorded up to seven times on a Spectrum 2000 spectrometer (Perkin Elmer, Wellesley, MA, USA), equipped with a Golden single-reflection accessory for Attenuated Total Reflection (ATR) measurements. Background scanning and correction were performed before testing the samples. Each spectrum was collected after 16 scans between 4000 and $600 \mathrm{~cm}^{-1}$ at intervals of $1 \mathrm{~cm}^{-1}$ with a resolution of $4 \mathrm{~cm}^{-1}$. The FTIR spectra were fitted by an automatic base line correction using OMNIC 4.0 software.

X-Ray Diffraction Analysis (XRD). The rice husk, the alkaline and SWE residues together with the bleached ones and the CNCs were analysed in an X-ray diffractometer (X'Pert PRO MPD PANalytical, The Netherlands) at environment temperatures. A monochromatic CuKa radiation $\left(\mathrm{k}=1.54 \mathrm{~A}^{\circ}\right)$ in the range of $2 \theta$ varying from $10^{\circ}$ to $60^{\circ}$ at a scan rate of $1^{\circ} / \mathrm{min}$. Xray diffraction data were processed and analysed using HighScore Plus 3.0 software (PANalytical, Inc.). The crystalline index (CrI) of the different samples was determined by referring to diffraction intensity of crystalline and amorphous regions according with the Segal empirical method ${ }^{30}$ after subtraction of the background signal. 
Thermogravimetric Analysis (TGA). The thermal behaviour was determined by dynamic thermogravimetric analysis (TGA) using a Mettler-Toledo TGA/SDTA 851 (Columbus, OH). Approximately $6 \mathrm{mg}$ of each sample was heated between $25^{\circ} \mathrm{C}$ and $600{ }^{\circ} \mathrm{C}$ at a heating rate of $10{ }^{\circ} \mathrm{C} \cdot \mathrm{min}^{-1}$ under a nitrogen atmosphere flow of $50 \mathrm{~mL} \cdot \mathrm{min}^{-1}$. The thermogravimetric (TG) and the derivative thermogravimetric (DTG) curves were obtained using STAR ${ }^{\mathrm{e}}$ Evaluation Software (Mettler-Toledo, Columbus, $\mathrm{OH}$ ). The maximum degradation temperature $\left(\mathrm{T}_{\max }\right)$ was determined by the DTG curves, while the mass loss percentage of each thermal degradation stage and the residue at the end of the test were calculated from the TG curves. The initial degradation temperature $\left(\mathrm{T}_{\text {onset }}\right)$ was determined by extrapolating the slope of the DTG curve in correspondence with the first local maximum in the second derivative thermogravimetric (D2TG) curve and down to the zero level of the DTG axis. All measurements were run in triplicate.

Scanning Electron Microscopy coupled with elemental analysis (SEM-EDX). SEM micrographs of the sedimented silica samples were obtained using a HITACHI TM-1000 scanning electron microscope equipped with an energy-dispersive X-ray spectroscopy (EDX) detector (Oxford Instruments). The samples were not coated previously.

\section{Results and discussion}

Cascade process for the isolation of bioactive arabinoxylans and cellulose nanocrystals

\section{from rice husk}

The integrated biorefinery process for the sequential fractionation of rice husk into bioactive hemicelluloses and cellulose nanocrystals (CNCs) is presented in Figure 1. The cascade process involves subcritical water extraction (SWE) of hemicelluloses as an alternative to 
alkaline extraction, prior to the isolation of CNCs using bleaching treatments and acid hydrolysis. The process has been monitored from the macro- to the nano dimensions in terms of chemical composition of the soluble extracts and insoluble residues, their morphology and thermal properties, and compared to the traditional alkaline process. The product appearance after each treatment, as well as the respective yields obtained from mass balances, are also included. The more aggressive conditions of the alkali treatment enhanced the release of the amorphous phase, thus leading to purer cellulosic materials after the bleaching treatment (whiter residues). The colour changes were less noticeable in the hydrothermal (SWE) approach, which also resulted in a higher yield of the insoluble residue after SWE (69\%) compared to the alkaline treatment $(54 \%)$. These results suggest the less effective removal of the non-cellulosic components from rice husk in terms of quantity, due to the milder conditions of the SWE. However, taking into consideration the soluble extract, SWE was more suitable offering $27.0 \%$ of soluble solids, whereas the alkali treatments yield $23.6 \%$ and $\mathrm{pH} 7.0$ for wheat bran. ${ }^{13}$

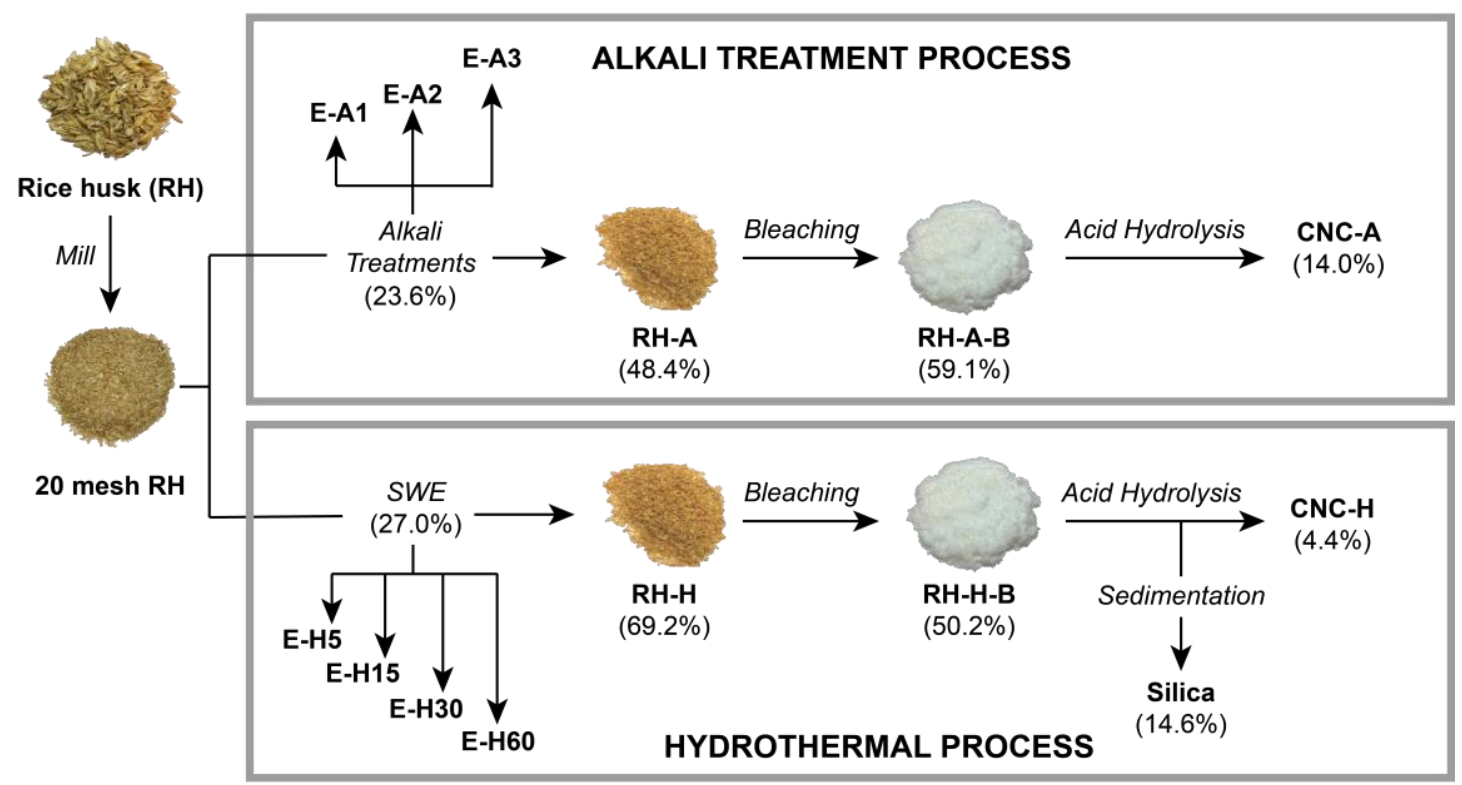


Figure 1. Schematic representation of the cascade bioprocess for rice husk valorization through two different approaches, common alkali-treatment process and an alternative hydrothermal process where subcritical water extraction (SWE) substitutes the traditional alkaline extraction. The gravimetric yields for each treatment were calculated based on the dry weight of the previous step.

\section{Extraction of bioactive arabinoxylan from rice husk: comparison of the hydrothermal} and alkaline process

The evolution of the extraction processes was evaluated in terms of monosaccharide composition and glycosidic linkage analysis, in order to correlate the potential functionality of the extracts in terms of antioxidant and antimicrobial capacity with their xylan content and molecular structure. Short extraction times during SWE resulted in extracts containing mainly glucose polymers (>80 wt $\%$ for the 5 min extract) (Figure 2a, Table 1), that can be attributed to the presence of residual starch coming from the rice husking process, as evidenced by the presence of t-Glc, 4-Glc and 4,6-Glc in the linkage analysis (Table 2). However, as the extraction time continued, the arabinoxylan purity in the extracts progressively increased, reaching a content of $69 \%$ and $84 \%$ in the $30 \mathrm{~min}$ and $60 \mathrm{~min}$ extracts, respectively (Figure 2a, Table 1). Likewise, starch was also initially extracted during the first alkaline cycle, and the xylan content increased in the second and the third alkaline extraction cycles. However, SWE offered higher overall xylan purities in the extracts obtained at longer extraction times compared to those obtained by alkali extraction (Figure 2a, Table 1).

The presence of phenolic acids (mainly ferulic acid, but also caffeic acid and p-coumaric acid) was only detected in the extracts from the subcritical water processes, with increasing overall content from $2.4-5.5 \mathrm{mg} \mathrm{g}^{-1}$ with prolonged extraction time. The level of phenolic acids was below detection limit for all the alkaline extracts, indicating that such functionalities of the rice husk were lost during the extraction process. Indeed, alkaline treatments are capable of 
cleaving the ester and ether linkages between the hydroxycinnamic acids and the cell wall

components, thus releasing them as free phenolic acids that were removed during the dialysis

of the extracts. ${ }^{31}$ On the other hand, the SWE process preserves the phenolic functionalities

covalently bound to the arabinoxylan populations, as we have previously reported for

262 feruloylated arabinoxylan extracted from wheat bran. ${ }^{13}$

Table 1. Monosaccharide composition (wt\%), number-average molar mass $\left(\mathrm{M}_{\mathrm{n}}\right)$ and weight-average molar mass $\left(\mathrm{M}_{\mathrm{w}}\right)$ of the rice husk extracts resulting from sequential fractionation by subcritical water extraction (E-SWE) and the three consecutive alkaline extractions (E-A).

\begin{tabular}{|c|c|c|c|c|c|c|c|}
\hline & \multicolumn{4}{|c|}{ Hydrothermal process } & \multicolumn{3}{|c|}{ Alkaline process } \\
\hline & $\overline{\text { E-H5 }}$ & E-H15 & E-H30 & E-H60 & E-A1 & E-A2 & E-A3 \\
\hline Total solid yields (\%) & $11.0 \pm 0.7$ & $3.9 \pm 0.1$ & $4.7 \pm 0.8$ & $7.4 \pm 0.5$ & $16.1 \pm 1.3$ & $5.2 \pm 0.7$ & $2.3 \pm 0.1$ \\
\hline $\begin{array}{l}\text { Carbohydrate content } \\
\left(\mathrm{mg} \mathrm{g}^{-1}\right)^{\mathrm{a}}\end{array}$ & $855.2 \pm 116.1$ & $770.4 \pm 63.0$ & $797.4 \pm 89.0$ & $907.1 \pm 17.5$ & $855.2 \pm 116.1$ & $770.4 \pm 63.0$ & $797.4 \pm 89.0$ \\
\hline $\operatorname{Ara}(\%)^{\mathrm{b}}$ & $2.0 \pm 0.2$ & $16.6 \pm 0.3$ & $15.3 \pm 2.3$ & $8.4 \pm 0.4$ & $6.5 \pm 3.1$ & $10.9 \pm 0.6$ & $10.6 \pm 1.5$ \\
\hline $\mathrm{Gal}(\%)^{\mathrm{b}}$ & $1.6 \pm 0.2$ & $4.2 \pm 0.3$ & $6.0 \pm 0.2$ & $4.7 \pm 0.1$ & $3.3 \pm 2.1$ & $2.1 \pm 0.1$ & $2.1 \pm 0.3$ \\
\hline Glc $(\%)^{\mathrm{b}}$ & $94.0 \pm 0.6$ & $55.4 \pm 2.1$ & $7.7 \pm 0.8$ & $3.1 \pm 0.3$ & $47.1 \pm 3.4$ & $3.7 \pm 0.4$ & $7.1 \pm 5.7$ \\
\hline $\mathrm{Xyl}(\%)^{\mathrm{b}}$ & $2.4 \pm 0.3$ & $23.8 \pm 1.5$ & $67.1 \pm 1.7$ & $80.7 \pm 1.0$ & $41.1 \pm 4.2$ & $78.0 \pm 0.7$ & $74.9 \pm 3.1$ \\
\hline $\operatorname{MeGlcA}(\%)^{\mathrm{b}}$ & n.d & n.d & $2.9 \pm 0.2$ & $2.5 \pm 0.3$ & $0.8 \pm 0.7$ & $3.7 \pm 0.4$ & $4.2 \pm 1.0$ \\
\hline $\operatorname{GalA}(\%)^{\mathrm{b}}$ & n.d & n.d & n.d & n.d & $0.4 \pm 0.1$ & $0.8 \pm 0.2$ & $0.4 \pm 0.3$ \\
\hline $\operatorname{GlcA}(\%)^{\mathrm{b}}$ & n.d & n.d & $1.0 \pm 0.0$ & $0.7 \pm 0.1$ & $0.5 \pm 0.1$ & $0.8 \pm 0.1$ & $0.7 \pm 0.0$ \\
\hline $\begin{array}{l}\text { Xylan content } \\
\left(\mathrm{mg} \mathrm{g}^{-1}\right)^{\mathrm{c}}\end{array}$ & $37.6 \pm 2.8$ & $310.5 \pm 15.2$ & $688.8 \pm 72.8$ & $836.9 \pm 13.9$ & $397.0 \pm 51.1$ & $723.3 \pm 37.4$ & $568.1 \pm 12.6$ \\
\hline Ara:Xyl ratio ${ }^{\mathrm{d}}$ & $0.82 \pm 0.08$ & $0.70 \pm 0.03$ & $0.23 \pm 0.04$ & $0.10 \pm 0.01$ & $0.15 \pm 0.07$ & $0.14 \pm 0.01$ & $0.14 \pm 0.01$ \\
\hline $\begin{array}{l}\text { Hydroxycinnamic } \\
\text { acid content }\left(\mathrm{mg} \mathrm{g}^{-1}\right)^{\mathrm{e}}\end{array}$ & $2.4 \pm 0.8$ & $5.0 \pm 1.2$ & $5.1 \pm 1.7$ & $5.5 \pm 0.7$ & n.d. & n.d. & n.d. \\
\hline $\begin{array}{l}\text { Ferulic acid } \\
(\mathrm{mg} / \mathrm{g})^{\mathbf{e}}\end{array}$ & $1.7 \pm 0.3$ & $3.2 \pm 0.8$ & $3.6 \pm 0.9$ & $4.3 \pm 0.5$ & n.d & n.d & n.d \\
\hline $\begin{array}{l}\text { Caffeic acid } \\
(\mathrm{mg} / \mathrm{g})^{\mathrm{e}}\end{array}$ & $0.3 \pm 0.2$ & $0.4 \pm 0.1$ & $0.4 \pm 0.4$ & $0.4 \pm 0.1$ & n.d & n.d & n.d \\
\hline $\begin{array}{l}\text { p-Coumaric acid } \\
(\mathrm{mg} / \mathrm{g})^{\mathbf{e}}\end{array}$ & $0.4 \pm 0.3$ & $0.8 \pm 0.3$ & $1.1 \pm 0.4$ & $0.8 \pm 0.1$ & n.d & n.d & n.d \\
\hline $\mathrm{M}_{\mathrm{n}}(\mathrm{g} / \mathrm{mol})^{\mathrm{f}}$ & 36810 & 4291 & 3254 & 2705 & 12150 & 8784 & 8128 \\
\hline $\mathrm{M}_{\mathrm{w}}(\mathrm{g} / \mathrm{mol})^{\mathrm{f}}$ & 691700 & 250600 & 59990 & 6499 & 271700 & 35970 & 35230 \\
\hline $\begin{array}{l}\mathrm{EC}_{50}(\mathrm{mg} / \mathrm{mg} \\
\mathrm{DPPH})^{\mathrm{g}}\end{array}$ & N/A & N/A & N/A & $9.6 \pm 0.6$ & N/A & N/A & $170 \pm 21$ \\
\hline $\begin{array}{l}\text { MIC L. innocua } \\
(\mathrm{mg} / \mathrm{mL})^{\mathrm{h}}\end{array}$ & N/A & N/A & N/A & $55.0 \pm 2.5$ & N/A & N/A & n.d \\
\hline $\begin{array}{l}\text { MIC E. coli } \\
(\mathrm{mg} / \mathrm{mL})^{\mathrm{h}}\end{array}$ & N/A & N/A & N/A & $95.0 \pm 2.5$ & N/A & N/A & n.d \\
\hline
\end{tabular}

a Total carbohydrate content reported after quantification by methanolysis and HPAEC-PAD.

${ }^{\mathrm{b}}$ Monosaccharide composition (in \%wt) of the total carbohydrate content. The values for fucose, rhamnose and mannose were not detected $(<0.1){ }^{20}$ 
d The Ara:Xyl ratio is calculated from the monosaccharide composition.

${ }^{\mathrm{e}}$ Hydroxycinnamic acid content calculated after saponification, silylation and GC-MS analysis. ${ }^{21}$

${ }^{\mathrm{f}}$ Average molar mass $\left(\mathrm{M}_{\mathrm{n}}\right.$ and $\left.\mathrm{M}_{\mathrm{w}}\right)$ of the polysaccharide populations is calculated from SEC-DRI

${ }^{g}$ Antioxidant activity (EC50) evaluated using the DPPH methodology. ${ }^{24}$

${ }^{\mathrm{h}}$ Antibacterial activity (MIC) evaluated by colorimetric methods.

n.d: not detected $(<0.1)$. N/A: non applicable

The fine molecular structure of the extracted polysaccharides was characterized by glycosidic linkage analysis of the permethylated alditol acetates by GC-MS (Table 2). In both processes, glucan populations that can be assigned to starch (as identified by the t-Glcp, 4-Glcp and 4,6Glc $p$ units), mixed-linkage $\beta$-glucan (corresponding with the t-Glcp, 3-Glcp and 4-Glcp), and short-chain type xyloglucan ${ }^{32}$ (t-Xyl $p$, t-Glcp, 4-Glcp and 4,6-Glcp) are extracted during the initial extraction steps, with a progressive enrichment of the xylan fractions with extraction time, in agreement with the monosaccharide composition (Table 1 and Figure 2a). Interestingly, the extracted arabinoxylan populations using SWE and alkaline process exhibit significant differences in terms of the substitution pattern. Alkaline extraction generates xylan populations with higher proportion of monosubstituted Xylp units compared to SWE, as evidenced by the relative amounts of the substituted 2,4-Xylp and 3,4-Xyl $p$ units, and the terminal t-Araf units. On the other hand, SWE generates xylan populations with interesting and distinct substitution patterns compared to the alkaline extracts. The presence of arabinopyranosyl units (t-Arap and 2-Arap) can be observed only in the SWE, which may indicate that SWE targets different xylan populations in rice husk compared to alkaline extraction or the degradation of the arabinopyranosyl units during alkaline conditions. In addition to this, a progressive decrease in the ratio of substituted Xylp units $(2,4-\mathrm{Xyl} p$ and 3,4-Xyl $p$ ) compared to the unsubstituted ones (4-Xylp), correlating with a decrease of the terminal arabinosyl units (t-Araf and t-Arap) can be observed with extraction times, which suggests the degradation of the Ara units due to the prolonged exposure to the subcritical water conditions. The distinct glycosidic linkage structures here presented for the SWE and 
alkaline xylan extracts from rice bran indicate the presence of noteworthy branching motifs in

301

302

303

304

305

306

307

308

309

310

311

312

313

rice xylans, which will be the subject of further investigations using advanced enzymatic and glycomic profiling.

Table 2. Glycosidic linkage analysis (\% mol.) of the rice husk extracts resulting from subcritical water extraction (E-SWE) and alkaline extractions (E-A).

\begin{tabular}{|c|c|c|c|c|c|c|c|c|}
\hline & \multirow[t]{2}{*}{ Linkage } & \multicolumn{4}{|c|}{ Hydrothermal process } & \multicolumn{3}{|c|}{ Alkaline process } \\
\hline & & \multirow{2}{*}{$\begin{array}{c}\text { E-H5 } \\
1.2 \pm 0.1\end{array}$} & \multirow{2}{*}{$\begin{array}{c}\text { E-H15 } \\
9.8 \pm 0.2\end{array}$} & \multirow{2}{*}{$\begin{array}{c}\text { E-H30 } \\
6.7 \pm 1.1\end{array}$} & \multirow{2}{*}{$\begin{array}{c}\text { E-H60 } \\
3.1 \pm 0.1\end{array}$} & E-A1 & \multirow{2}{*}{$\begin{array}{c}\text { E-A2 } \\
8.6 \pm 0.2\end{array}$} & \multirow{2}{*}{$\frac{\text { E-A3 }}{8.4 \pm 0.8}$} \\
\hline t-Araf & Araf- $(1 \rightarrow$ & & & & & $4.7 \pm 1.2$ & & \\
\hline $\mathrm{a} p$ & Arap $-(1 \rightarrow$ & $2 \pm 0.0$ & $3.0 \pm 0.0$ & $2.4 \pm 0.1$ & $0.6 \pm 0.6$ & n.d & $\begin{array}{c}8.6 \pm 0.2 \\
\text { n.d }\end{array}$ & $\begin{array}{c}8.4 \pm 0.8 \\
\text { n.d }\end{array}$ \\
\hline 2-Araf & $\rightarrow 2)$-Araf- $(1 \rightarrow$ & $0.2 \pm 0.0$ & $1.5 \pm 0.0$ & $1.3 \pm 0.6$ & $.2 \pm 0.2$ & $0.8 \pm 0.4$ & $1.5 \pm 0.3$ & $1.2 \pm 0.1$ \\
\hline 3-Araf & $\rightarrow 3)$-Araf- $(1 \rightarrow$ & $0.5 \pm 0.0$ & $2.3 \pm 0.0$ & $1.6 \pm 0.1$ & $4 \pm 0.1$ & $1.2 \pm 1.2$ & $0.7 \pm 0.1$ & $0.5 \pm 0.0$ \\
\hline 5-Araf & $\rightarrow 5)$-Araf-(1 $\rightarrow$ & $0.3 \pm 0.0$ & $1.8 \pm 0.0$ & $1.7 \pm 0.1$ & $1.0 \pm 0.2$ & $0.5 \pm 0.2$ & $0.4 \pm 0.1$ & $0.4 \pm 0.0$ \\
\hline \multirow[t]{2}{*}{ 2-Arap } & $\rightarrow 2$ - $-\mathrm{Ar}$ & n.d & n.d & $2.2 \pm 0.5$ & $0.6 \pm 0.1$ & n.d & n.d & n.d \\
\hline & Total Ara & $2.4 \pm 0.2$ & $18.4 \pm 0.3$ & $15.8 \pm 2.4$ & $8.6 \pm 0.5$ & $7.2 \pm 3.3$ & $11.2 \pm 0.6$ & $10.6 \pm 1.5$ \\
\hline \multirow{5}{*}{$\begin{array}{l}\text { t-Xyl } p \\
4-X y l p \\
\text { 2,4-Xyl } p \\
\text { 3,4-Xyl } p \\
\text { 2,3,4-Xylp }\end{array}$} & Xyl $p-(1 \rightarrow$ & $0.3 \pm 0.1$ & $2.4 \pm 0.0$ & $6.5 \pm 0.7$ & $8.7 \pm 0.4$ & $1.3 \pm 0.1$ & $2.5 \pm 0.4$ & $2.2 \pm 0.2$ \\
\hline & $\rightarrow 4)-\mathrm{Xyl} p-(1 \rightarrow$ & $1.8 \pm 0.1$ & \multirow{2}{*}{$\begin{array}{c}19.0 \pm 0.4 \\
2.8 \pm 1.0\end{array}$} & $57.0 \pm 0.7$ & $69.1 \pm 0.3$ & \multirow{2}{*}{$\begin{array}{c}35.1 \pm 3.4 \\
1.4 \pm 0.2\end{array}$} & $66.0 \pm 0.0$ & \multirow{2}{*}{$\begin{array}{c}64.0 \pm 2.0 \\
47+0.6\end{array}$} \\
\hline & $\rightarrow 2,4)-\mathrm{Xyl} p-(1 \rightarrow$ & $0.4 \pm 0.1$ & & $1.0 \pm 0.1$ & n.d & & $4.6 \pm 0.1$ & \\
\hline & $\rightarrow 3,4)-\mathrm{Xyl} p-(1 \rightarrow$ & $0.3 \pm 0.0$ & $2.0 \pm 0.2$ & 4.6 & $4.5 \pm 0.3$ & $6.3 \pm 0.4$ & $4.8 \pm 0.1$ & $3.9 \pm 0.3$ \\
\hline & $\begin{array}{c}\rightarrow 2,3,4)-\mathrm{Xyl} p- \\
\quad(1 \rightarrow\end{array}$ & $0.1 \pm 0.0$ & $0.2 \pm 0.0$ & & & $0.9 \pm 0.3$ & 0.6 & $0.1 \pm 0.1$ \\
\hline \multicolumn{2}{|r|}{ Total Xyl } & $2.9 \pm 0.4$ & 26.4 & 69.4 & $82.4 \pm 0.9$ & $45.1 \pm 4.1$ & $79.9 \pm 0.7$ & $74.9 \pm 3.1$ \\
\hline$t-G$ & Glcn & $6.3 \pm 0.1$ & 3.3 & $\overline{0 c}$ & 0 & $1.9 \pm 0.6$ & 0.07 & $0.4 \pm 0.1$ \\
\hline & $\rightarrow 3)-($ & .1 & 0.6 & 0. & 0.7 & $0.3 \pm 0.2$ & 0.15 & $0.5 \pm 0.1$ \\
\hline 4-Glcp & $\rightarrow 4)$-Glcp-(1 $\rightarrow$ & $81.9 \pm 0.5$ & $44.7 \pm 1.8$ & $4.8 \pm 0.5$ & $1.4 \pm 0.1$ & $38.7 \pm 2.8$ & $1.85 \pm 0.07$ & $5.7 \pm 3.6$ \\
\hline \multirow[t]{2}{*}{ 4,6-Glcp } & $\rightarrow 4,6)-$ Glcp-( $(1 \rightarrow$ & $4.5 \pm 0.1$ & $2.7 \pm 0.1$ & $0.2 \pm 0.1$ & $0.1 \pm 0.0$ & $2.1 \pm 0.1$ & $1.12 \pm 0.09$ & $0.6 \pm 0.2$ \\
\hline & al Glc & $93.2 \pm 0.7$ & $51.3 \pm 2.1$ & $6.6 \pm 0.7$ & $2.6 \pm 0.2$ & $43.1 \pm 3.6$ & $3.2 \pm 0.4$ & $7.1 \pm 4.0$ \\
\hline $\mathrm{t}-\mathrm{Gal} p$ & 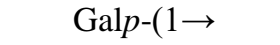 & $0.4 \pm 0.1$ & $1.2 \pm 0.0$ & $3.8 \pm 0.0$ & $2.8 \pm 0.0$ & $2.8 \pm 0.3$ & $1.3 \pm 0.1$ & $1.3 \pm 0.0$ \\
\hline & $\rightarrow 3)$-Galp-(1 $\rightarrow$ & $0.7 \pm 0.0$ & $1.3 \pm 0.1$ & 0.9 & $0.8 \pm 0.0$ & $0.1 \pm 0.0$ & $0.3 \pm 0.0$ & $0.3 \pm 0.9$ \\
\hline \multirow[t]{2}{*}{ 3,6-Galp } & 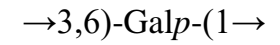 & $0.5 \pm 0.1$ & $1.4 \pm 0.2$ & $0.6 \pm 0.0$ & $0.3 \pm 0.01$ & $0.1 \pm 0.1$ & $0.2 \pm 0.0$ & $0.5 \pm 0.2$ \\
\hline & Total Gal & $1.6 \pm 0.2$ & $3.9 \pm 0.3$ & $5.2 \pm 0.2$ & $4.0 \pm 0.1$ & $3.0 \pm 0.4$ & $1.77 \pm 0.08$ & $2.1 \pm 0.2$ \\
\hline
\end{tabular}

n.d: not detected $(<0.1)$.

The molar mass distributions and average molar masses of the polymeric fractions were determined by SEC analyses (Figure $2 \mathbf{b}$ and Table 1). The initial alkali and SWE extracts showed bimodal molar mass distributions with two main populations, a high molar mass fraction $\left(10^{5}-10^{6} \mathrm{~g} \cdot \mathrm{mol}^{-1}\right)$ attributed to starch, and a low molar mass fraction $\left(10^{3}-10^{5}\right.$ $\mathrm{g} \cdot \mathrm{mol}^{-1}$ ) that can be assigned to xylan. The intensity of the starch peak decreased with the extraction times/cycles, in agreement with the compositional analyses (Table 1). On the other 
hand, the second and the third alkali extracts and the SWE for 60 min exhibited a monomodal distribution corresponding to the extracted xylan populations $\left(10^{3}-10^{5} \mathrm{~g} \cdot \mathrm{mol}^{-1}\right)$ (Figure $\left.2 \mathbf{b}\right)$. Alkaline extraction offered overall xylan populations with higher molar mass $\left(\mathrm{M}_{\mathrm{w}}=3.5 \cdot 10^{4}\right.$ $\left.\mathrm{g} \cdot \mathrm{mol}^{-1}\right)$ compared to the hydrothermal process $\left(\mathrm{M}_{\mathrm{w}}=6.5 \cdot 10^{3} \mathrm{~g} \mathrm{~mol}^{-1}\right)$ (Table 1). The high $\mathrm{pH}$ conditions during the alkali treatment lead to the break of the ferulic crosslinks in the rice husk, thus liberating arabinoxylans with higher molar mass, but without the covalently attached phenolic functionalities. In contrast, SWE offers xylan populations with overall lower molar mass, but with preserved phenolic acids (feruloylation). Subcritical water may induce hydrolytic processes resulting in chain scission of the hemicellulosic backbone, as we have reported in previous studies on wheat $\operatorname{bran}^{13}$ and hardwoods ${ }^{33}$. In order to avoid the propagation of the autohydrolysis processes induced by the acidification of the extraction media by the release of the native acetylations present in the hemicelluloses, the control of the $\mathrm{pH}$ is a critical factor. ${ }^{33-35}$ Indeed, the end $\mathrm{pH}$ values after the extraction were lower than the initial $\mathrm{pH}$ value fixed at 7.0 reaching values close to $\mathrm{pH} 5$, which demonstrates the presence of moderately acetylated hemicelluloses in rice husk. The use of buffered conditions could be explored in further studies to maintain the $\mathrm{pH}$ levels during water extraction and assess its influence on the yields and molecular structure of the isolated arabinoxylan fractions.

The radical scavenging activity of the extracts with the highest xylan content from the alkaline (E-A3, third cycle) and SWE processes (E-H60, 60 min) was assessed against the $\mathrm{DPPH}^{\bullet}$ radical (Figure 2c). E-H60 reacted moderately with the DPPH', reaching the steady state after $1 \mathrm{~h}$, whereas the alkaline extract reacted much more slowly and reached the steady state within $5 \mathrm{~h}$. Moreover, SWE extract showed significant scavenging activity $\left(\mathrm{EC}_{50}\right.$ value of 9.6 $\pm 0.6 \mathrm{mg} / \mathrm{mg} \mathrm{DPPH}$ ), whereas the alkaline extract showed a 18 -fold lower antioxidant 
capacity (EC50 value of $170 \pm 21 \mathrm{mg} / \mathrm{mg}$ DPPH) (Table 1, Figure 2c). The most abundant

339 phenolic compounds in rice husk are p-coumaric and ferulic acid, with $\mathrm{EC}_{50}$ values of 0.2 $\mathrm{mg} / \mathrm{mg} \mathrm{DPPH}^{\cdot}$ and $20.8 \mathrm{mg} / \mathrm{mg} \mathrm{DPPH}^{\cdot}$, respectively. Therefore, it is reasonable to assign the antioxidant activity in the SWE extracts to the presence of phenolic acids covalently bound to

342 xylan, which have been preserved during the extraction process, (Table 1), in line with was 343 previously observed for feruloylated arabinoxylans from wheat bran. ${ }^{13}$

A

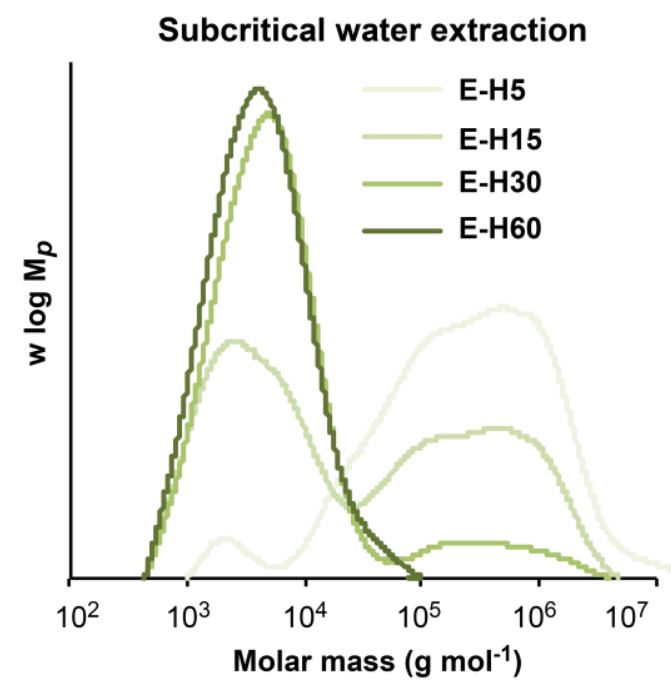

B

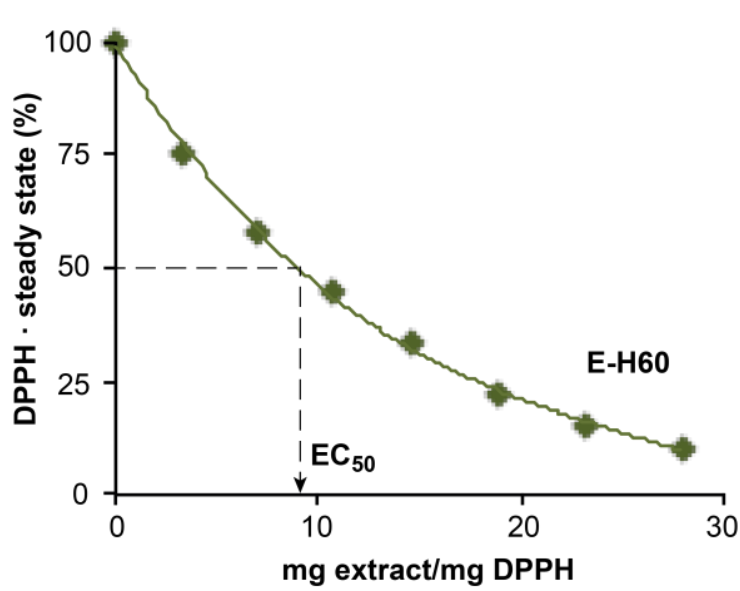

Alkaline extraction

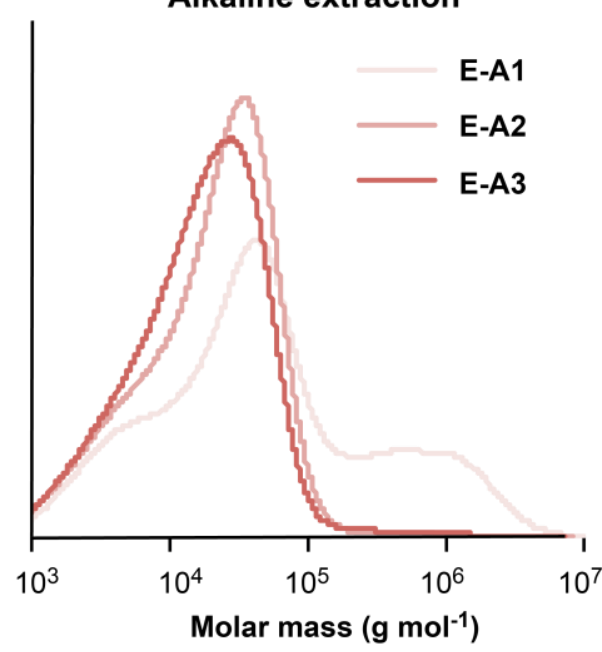

Alkaline extraction

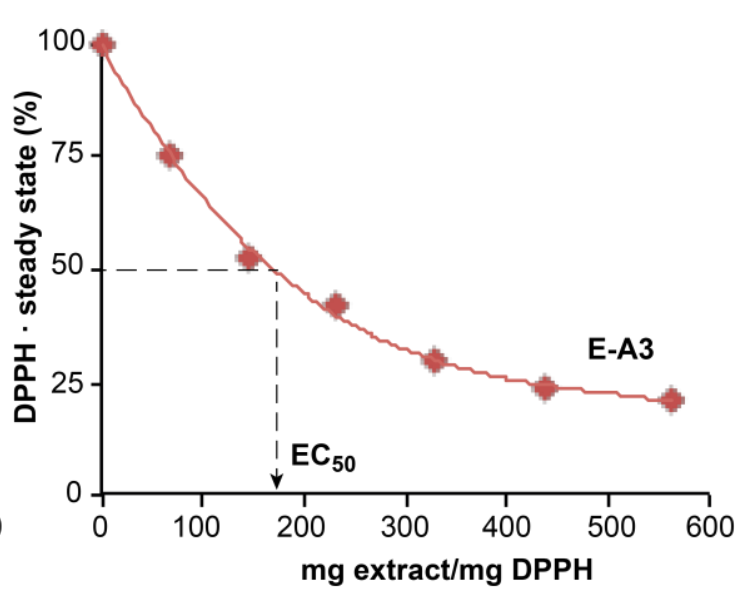

Figure 2. Characterization of the rice husk extracts resulting from sequential fractionation by subcritical water extraction (E-H) and the three consecutive alkaline extractions (E-A). (A) Molar mass distributions. (B) Percentage of DPPH remaining at the steady state versus the mass ratio of extract to DPPH for the rice husk extracts with the highest xylan content, showing the parameter $\mathrm{EC}_{50}$. 
350 The hemicellulosic extract obtained from the last step of the SWE (E-H60) inhibited the

351 microbial growth of L. innocua and E. coli, the gram negative bacteria being significantly

352 more resistant $(\mathrm{MIC}=95 \pm 2.5 \mathrm{mg} / \mathrm{mL})$ than the gram positive bacteria $(\mathrm{MIC}=55 \pm 2.5 \mathrm{mg} / \mathrm{mL})$.

353 Unlike for SWE extract, no antimicrobial effects were observed for the extract obtained from 354 the last alkali treatment (E-A3). The obtained results confirm the best efficiency of SWE at 355 preserving the functionalities and bioactivity of the xylan fractions of rice husk, although it

356

357

358

359

360

\section{Production of cellulose nanocrystals (CNCs) from the insoluble fractions:} characterization from the macro to the nano dimensions

The yields and the chemical composition (carbohydrate, Klason lignin, ash, and extractive content) of rice husk and the insoluble samples were monitored after each processing step (Table 3). In the initial rice husk $(\mathrm{RH})$, the glucose (Glc) content mainly arises from the presence of cellulose but also from the residual starch and minor mixed-linkage $\beta$-glucan and xyloglucan populations. In the insoluble fractions after the subsequent treatment steps, however, the relative cellulose content can be directly assigned to the percentage of glucose, without considering the presence of residual starch and $\beta$-glucans that are removed in the soluble phases. The hemicellulose/pectin content is measured as the percentage of the remaining sugars and includes arabinoxylan and the minor arabinogalactan (pectic) populations. In general, the raw rice husk contained $35.1 \mathrm{wt} \%$ glucans (mainly cellulose), 
$19.3 \mathrm{wt} \%$ hemicelluloses/pectin, $16.8 \mathrm{wt} \%$ lignin, and $17.0 \mathrm{wt} \%$ ash, in the range of those previously reported for rice husk. ${ }^{36}$

As expected, the cellulose content progressively increased in the insoluble fraction throughout the hemicellulose extraction treatments (hydrothermal and alkaline) and the subsequent bleaching and hydrolysis, due to the removal of the amorphous materials. Nonetheless, significant differences were observed between the traditional (alkaline) and the hydrothermal (SWE) processes. The alkali treatment removed the main part of the inorganic silica (ashes), as well as a part of the lignin and hemicellulose/pectin content. ${ }^{36}$ SWE was particularly selective to isolate the hemicelluloses, but it did not alter much the Klason lignin and ash content of the husk. The most significant reduction in Klason lignin was achieved during the bleaching treatments, their contents being $5.5 \%$ and $8.4 \%$, respectively in the RH-A-B and RH-H-B samples. The high ash content in the RH-H-B samples (16.6\%) is also remarkable, in contrast with RH-A-B samples (3.5\%). These differences could be attributed to the specificity of SWE at the extraction of hemicelluloses, and the harsh nature of the alkaline treatment, which disrupts the crosslinked structure of rice husk releasing lignin fragments. Moreover, the neutral conditions in SWE prevents silica extraction (main constituent of the ashes) to the liquid phase and remain in the insoluble residue; whereas silica in turn are much more soluble in the alkaline medium as silicic acid.

During the hydrolytic treatment with sulphuric acid after bleaching, hemicelluloses and pectin were hydrolysed together with the amorphous part of the cellulose and became soluble, thus obtaining cellulosic fractions with hemicellulose content of $1 \%$ or lower in both cases. The CNC purification process consisted of 1-week dialysis, sonication and final centrifugation to remove the largest particles. Interestingly, in the case of the bleached sample resulting from the SWE process (RH-H-B sample) with high ash content (16.6\%), the hydrolysis stage for 
the $\mathrm{CNC}$ isolation also enables the recovery of silica particles from the $\mathrm{CNC}$ suspensions. The

silica particles were sedimented during the centrifugation, together with the larger cellulosic aggregates. However, around $2 \%$ of the ash from the initial RH-H-B sample remains in the suspension and justifies the high ash content found and the low yield in the $\mathrm{CNC}-\mathrm{H}$.

Table 3. Chemical composition (in \%wt) of rice husk and the samples obtained after the different process steps to obtain CNCs.

\begin{tabular}{|c|c|c|c|c|c|c|c|}
\hline & \multirow[t]{2}{*}{ Rice Husk } & \multicolumn{3}{|c|}{ Alkali process } & \multicolumn{3}{|c|}{ Hydrothermal process } \\
\hline & & RH-A & RH-A-B & CNC-A & SWE & RH-H-B & CNC-H ${ }^{\mathrm{i}}$ \\
\hline Yields $(\% \mathrm{DW})^{\mathrm{a}}$ & N/A & 48.4 & 59.1 & 14.0 & 69.2 & 50.2 & 4.4 \\
\hline $\begin{array}{l}\text { Carbohydrate } \\
\text { content }\left(\mathrm{mg} \mathrm{g}^{-1}\right)^{\mathrm{b}}\end{array}$ & $544.8 \pm 12.7$ & $48.7 \pm 24.1$ & $920.1 \pm 2.0$ & $951 \pm 54.5$ & $470.9 \pm 9.3$ & $953.7 \pm 98.0$ & $558.0 \pm 56.0$ \\
\hline $\operatorname{Ara}(\%)^{\mathrm{c}}$ & $3.3 \pm 0.2$ & $2.9 \pm 0.1$ & $1.5 \pm 0.1$ & n.d. & $0.8 \pm 0.1$ & $0.3 \pm 0.0$ & n.d. \\
\hline $\operatorname{Gal}(\%)^{\mathrm{c}}$ & $1.7 \pm 0.3$ & $0.9 \pm 0.0$ & $0.1 \pm 0.0$ & n.d. & n.d. & $<0.1$ & n.d. \\
\hline $\operatorname{Glc}(\%)^{\mathrm{c}}$ & $64.4 \pm 2.2$ & $79.9 \pm 0.4$ & $80.0 \pm 0.3$ & $98.9 \pm 0.1$ & $78.1 \pm 0.5$ & $85.6 \pm 0.2$ & $99.9 \pm 0.0$ \\
\hline $\mathrm{Xyl}(\%)^{\mathrm{c}}$ & $30.6 \pm 1.8$ & $16.3 \pm 0.3$ & $18.5 \pm 0.4$ & $1.1 \pm 0.1$ & $21.1 \pm 0.5$ & $14.1 \pm 0.2$ & $<0.1$ \\
\hline Glucans $\left(\mathrm{mg} \mathrm{g}^{-1}\right)^{\mathrm{d}}$ & $350.9 \pm 3.8$ & $598.2 \pm 22.1$ & $735.8 \pm 1.0$ & $941.1 \pm 53.4$ & $367.8 \pm 7.2$ & $816.5 \pm 0.2$ & $558.0 \pm 56.0$ \\
\hline $\begin{array}{l}\text { Hemicellulose/ } \\
\text { pectin }\left(\mathrm{mg} \mathrm{g}^{-1}\right)^{\mathrm{e}}\end{array}$ & $193.9 \pm 16.5$ & $150.4 \pm 2.0$ & $191.5 \pm 4.2$ & $10.3 \pm 1.1$ & $103.6 \pm 2.38$ & $137.3 \pm 12.3$ & n.d. \\
\hline $\begin{array}{l}\text { Klason lignin } \\
(\%)^{\mathrm{g}}\end{array}$ & 16.8 & 14.7 & 5.5 & N/A & 22.0 & 8.4 & N/A \\
\hline $\operatorname{Ash}(\%)^{\mathrm{h}}$ & $17.0 \pm 0.2$ & $5.8 \pm 1.2$ & $3.5 \pm 0.2$ & $3.0 \pm 2.0$ & $17.4 \pm 0.7$ & $16.6 \pm 0.1$ & $39.0 \pm 1.0$ \\
\hline Extractives $(\%)^{\mathrm{i}}$ & $5.46 \pm 0.01$ & N/A & N/A & N/A & N/A & N/A & N/A \\
\hline
\end{tabular}

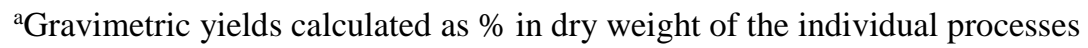

${ }^{\mathrm{b}}$ Total carbohydrate content after quantification by 2-step sulphuric acid hydrolysis and HPAEC-PAD.

${ }^{\mathrm{c}}$ Monosaccharide composition (in \%wt) of the total carbohydrate content. Fucose, rhamnose, mannose, galacturonic and glucuronic acid were not detected $(<0.1)$.

${ }^{\mathrm{d} C}$ Cellulose content reported as the total Glc content

${ }^{\mathrm{e} H e m i c e l l u l o s e}$ and pectin content reported as the total $\mathrm{Xyl}+\mathrm{Ara}+\mathrm{Gal}$ content

fLignin content determined by Tappi test method T222 om-06

${ }^{\mathrm{g}}$ Ash content determined by thermogravimetric analysis

hextractives determined by Soxhlet extraction in water/ethanol

${ }^{\mathrm{i}} \mathrm{CNC}-\mathrm{H}$ obtained after centrifugation of the CNC suspension for the separation of larger cellulosic aggregates and silica particles.

n.d: not detected. N/A: non applicable.

The morphological surface changes during the hydrothermal and alkaline processes were followed by SEM (Figure 3A). The fibre bundles of the rice husk remained after alkali extraction and SWE, which indicates the retention of the lignin fraction acting as a binder in the fibre components and preserving the bundle shape during both treatments. Nonetheless, 
during the alkali treatment a large part of the pectin and hemicellulose fraction was removed, thus opening the cell walls for the further treatments of rice husk. Most of the lignin was removed after the bleaching treatments, liberating the cellulosic fibres. However, the bleached materials after the hydrothermal treatment showed the presence of some fibre bundles and undisrupted tissue fragments, due to the lower effectiveness of SWE at quantitatively removing the non-cellulosic material.

The morphology and size distribution of the CNCs produced through both processes were studied by AFM (Figure 3B), including the distribution of the particle diameters (D) and lengths (1) of the CNCs. The obtained CNCs had the typical rod-like aspect mainly due to the strong hydrogen bonds established between them. ${ }^{19}$ The length (l) and diameter (D) distributions of the CNCs from rice husk were in the common range expected for CNCs isolated from plant biomass (diameter: $2-20 \mathrm{~nm}$ and length: 100-600 nm). ${ }^{37}$ The diameter dispersion for both obtained CNCs range from 2.5 to $8 \mathrm{~nm}$, which is higher than those reported for forest residues using the same $\mathrm{CNC}$ isolation procedure ${ }^{18}$ and lower than other CNC diameter values obtained previously for rice husk (ranging from $15-50 \mathrm{~nm}$ ). ${ }^{10,36}$ These discrepancies can be justified since these size parameters can be affected by the nature of the lignocellulosic raw material, mechanical process, pre-treatment and conditions of the acid hydrolysis and purification step. ${ }^{38}$ On the other hand, the length dispersion values are slightly lower for the CNC-A (105-465 nm) than for the CNC-H (135-495 nm) and similar to those obtained for $\mathrm{CNC}$ from pine-cones by using the same $\mathrm{CNC}$ isolation procedure. ${ }^{18}$

As it was mentioned earlier, the hydrothermal process also enables the recovery of silica particles from the CNC suspensions after acid hydrolysis of the bleached samples (RH-H-B) and centrifugation. The morphology of the sedimented particles shows large aggregates with broad size heterogeneity, between $9-54 \mu \mathrm{m}$ of diameter (Figure 3C). The elemental analysis of the sedimented particles by energy dispersive X-ray spectroscopy (EDX) reveals a large 
abundance of $\mathrm{Si}$, thus confirming the successful isolation of a silica rich fraction (Figure 3C).

447 This is a proof of concept for the simultaneous recovery of silica particles and CNCs with the 448 hydrothermal approach. Further efforts must be devoted to optimize the hydrolytic conditions 449 to improve the low yield of CNCs obtained using the hydrothermal process, and for the 450 recovery of the silica particles after the acid hydrolysis step at larger scales using technologies 451 such as sedimentation or membrane filtration. Silica particles constitute a valuable by-product 452 with numerous applications in the glass, foundries, construction, ceramics and the chemical 453 industry. Moreover, it is also used as functional filler for paints, plastics, rubber, and as silica 454 sand in water filtration and agriculture.

455 


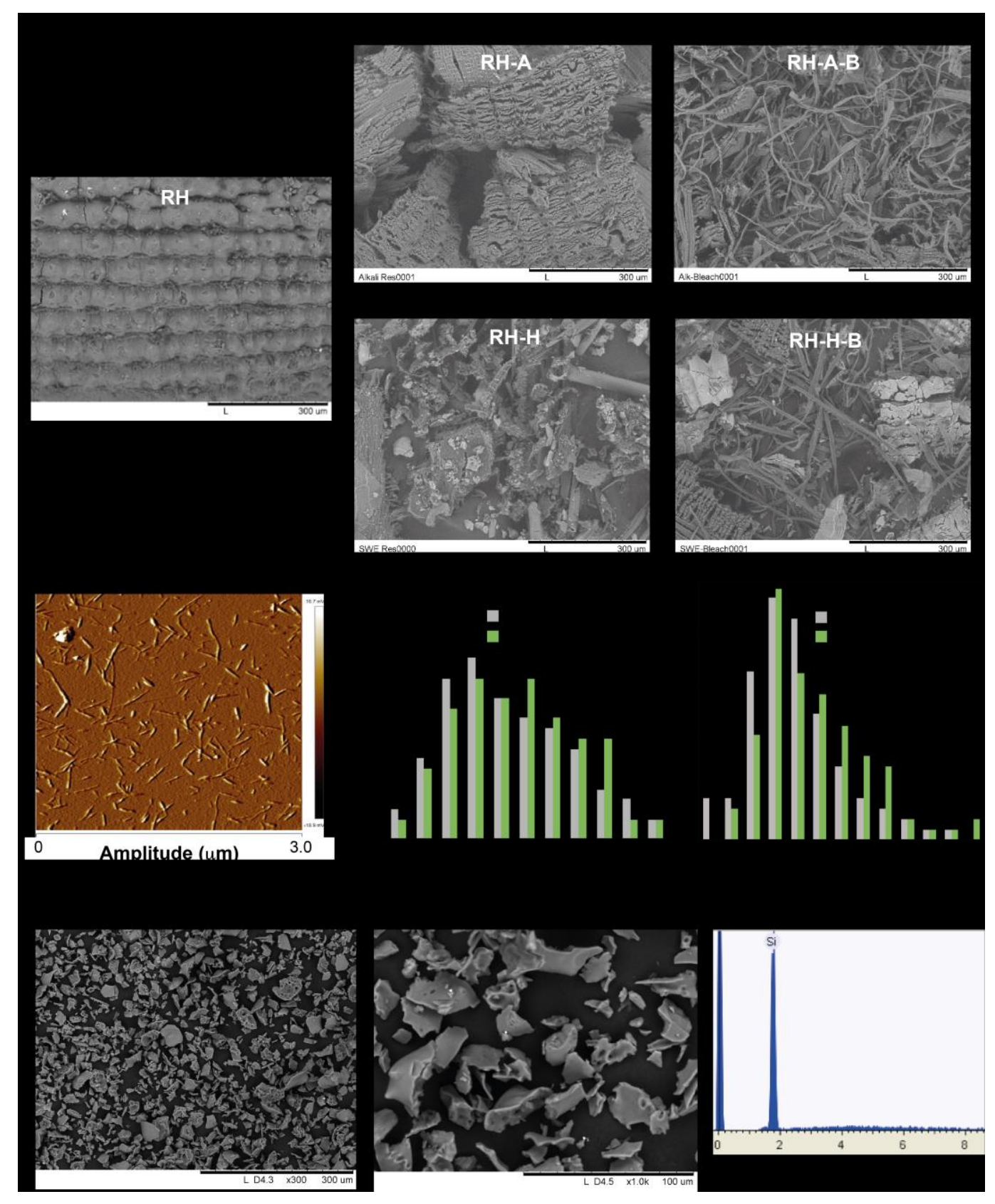

457 Figure 3. Morphological evolution of the isolation of cellulose nanocrystals and silica particles from

458 rice husk: (A) Scanning electron micrographs of the solid fractions of untreated rice husk (RH), rice 459 husk after alkali treatment (RH-A), rice husk after alkaline and bleaching (RH-A-B), rice husk after 460 subcritical water extraction (RH-H), and rice husk after SWE and bleaching (RH-H-B). (B)

461 Morphology of the cellulose nanocrystals (CNCs): AFM image of the isolated CNCs in amplitude 462 mode and size distributions of the CNCs obtained in the alkali-treatment process (grey bars) (CNC-A) 463 and the hydrothermal process (green bars) $(\mathrm{CNC}-\mathrm{H})$. Averaged particle diameter and length values are 464 shown from the analyses of 100 individual CNC particles using image analyses. (C) Morphology of 
the sedimented silica particles: Scanning electron micrographs at different magnifications $(\times 300$ and $\times 1000$ ); energy dispersive $X$-ray analysis of the surfaces.

The structural and thermal properties of the cellulosic fractions were evaluated using X-ray diffraction, Fourier-transform infrared spectroscopy (FTIR) and thermogravimetric analyses. The X-ray diffraction patterns (Figure 4A) exhibit in all samples the typical crystalline peaks of type I cellulose $\left(2 \theta: 15-16^{\circ}[110], 22^{\circ}\right.$ [200]), as reported by other authors. ${ }^{10,18,36}$ As expected, these peaks become more defined along the conversion from macro- to nanodimension, due to the progressive removal of the amorphous phase. This increase resulted in a higher degree of crystallinity as the CNCs isolation processes progressed (Table 4). During the alkaline treatment, the highest CrI increment was observed, in line with the higher increase in the cellulose content of this insoluble fraction. Comparing both alkaline and hydrothermal processes, the latter yield less crystalline samples throughout the production of CNCs, due to its lower effectiveness at removing the amorphous components of the rice husk.

The evolution of the chemical changes induced by the different treatments during the process for isolation of the CNCs was monitored by FTIR (Figure 4B). The alkali-treated samples and the corresponding bleached and hydrolysed samples showed a higher peak in the region related to the stretching vibrations of $\mathrm{OH}$ groups of the cellulose $\left(3330 \mathrm{~cm}^{-1}\right)^{39}$ when compared to the untreated rice husk, due to the relative increase in the hydrogen bond strength caused by the removal of the amorphous components present in the untreated material. ${ }^{10,18}$ This change in the FTIR spectra was less noticeable in the samples obtained from the hydrothermal process, due to the lower effectiveness of the SWE process to disrupt the tissue structure and release the different amorphous components. The peaks at approximately 17001590 (carboxylic acid), 1509 (acetyl group) and $1250 \mathrm{~cm}^{-1}$ (methyl ester group), which are 
491 the peak at approximately $800 \mathrm{~cm}^{-1}$ appearing in the rice husk is retained in all the samples

492 obtained from the hydrothermal process, and it can be to the amorphous silica $\left(\mathrm{SiO}_{2}\right)$.

A Alkaline process
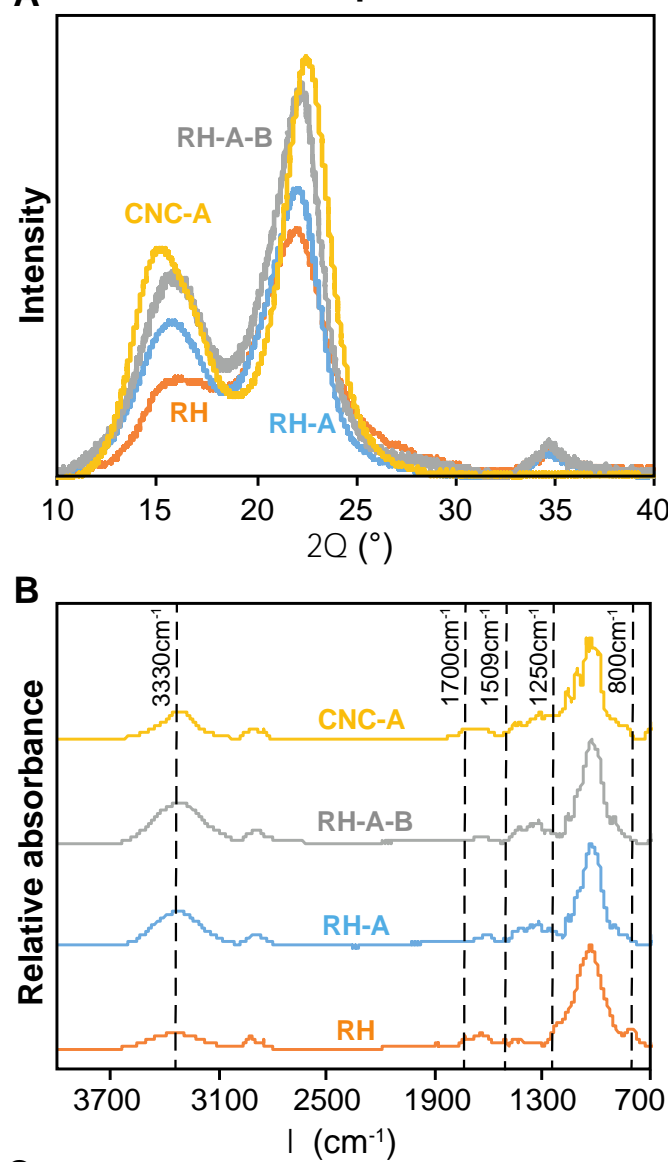

C

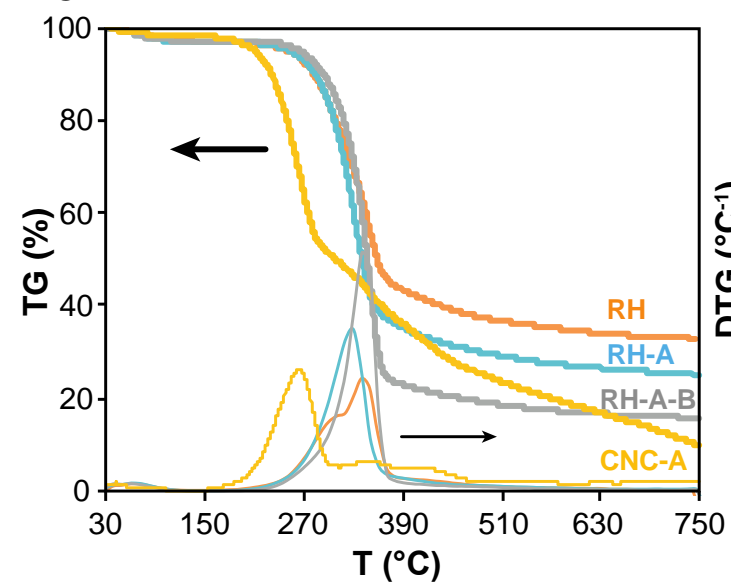

Hydrothermal process
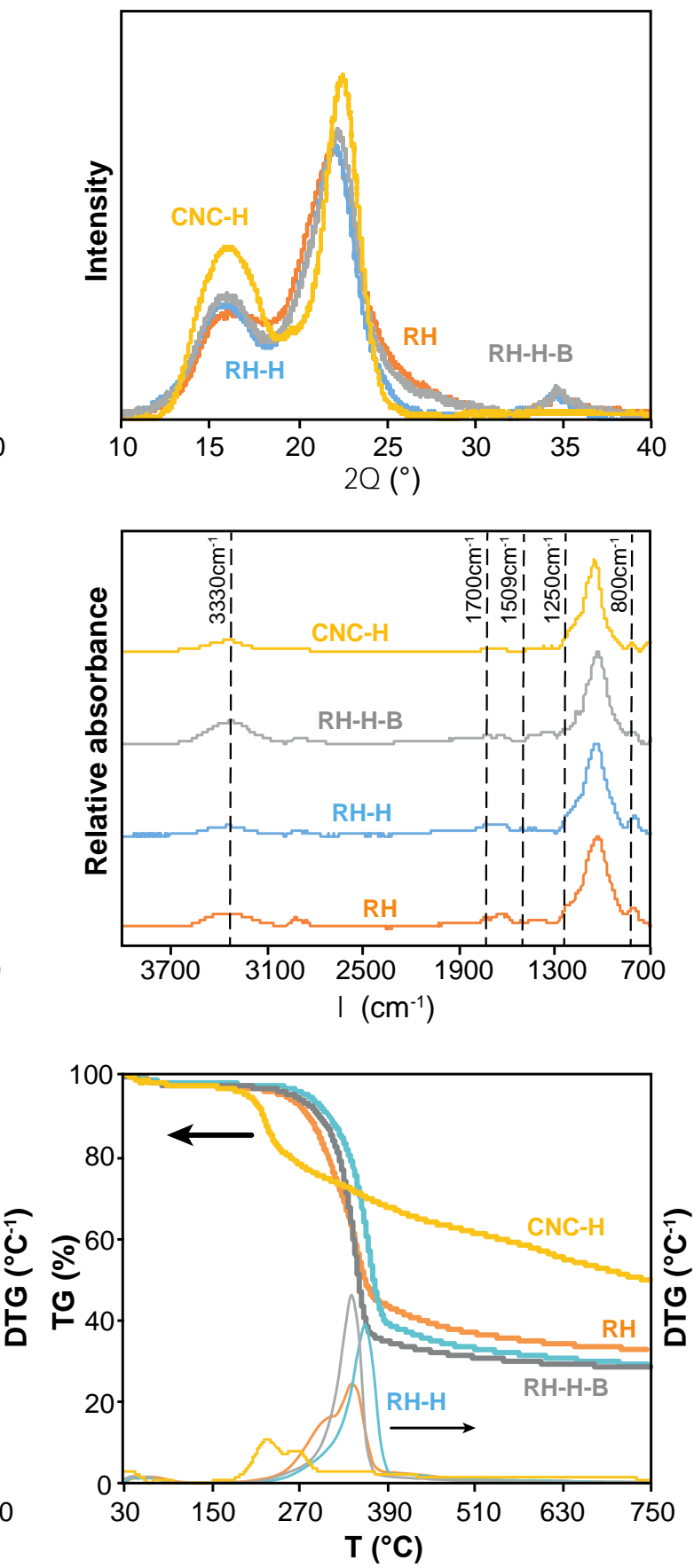

493 
502

Figure 4. Structural and thermal properties of the rice husk $(\mathrm{RH})$ and the insoluble fractions during the alkaline (RH-A: alkali treated; RH-A-B: alkali-bleached treated; CNC-A: cellulose nanocrystals) and hydrothermal treatments (RH-H: SWE treated; RH-H-B: SWE-bleached treated; CNC-H: cellulose nanocrystals): A. X-ray diffraction patterns; B. FTIR spectra; C. Thermal decomposition: thermogravimetric (TG) and derivative (DTG) curves.

Table 4. Crystallinity index (from X-ray diffraction) and thermogravimetric parameters of the rice husk (RH) and the insoluble fractions from the alkali and hydrothermal process.

\begin{tabular}{|l|c|c|c|c|c|c|c|}
\hline \multirow{2}{*}{ Sample } & XRD & \multicolumn{7}{|c|}{ Thermogravimetric parameters } & Residue \\
\cline { 2 - 8 } & & $\mathrm{CrI}(\%)$ & \multicolumn{2}{|c|}{$[\mathbf{2 5 - 1 5 0}]^{\circ} \mathbf{C}$} & \multicolumn{3}{|c|}{$[\mathbf{1 8 0 - 5 5 0}]^{\circ} \mathbf{C}$} \\
\cline { 3 - 8 } & & $\begin{array}{c}\text { Mass loss } \\
(\%)\end{array}$ & $\mathrm{T}_{\max }\left({ }^{\circ} \mathrm{C}\right)$ & $\mathrm{T}_{\text {onset }}\left({ }^{\circ} \mathrm{C}\right)$ & $\begin{array}{c}\text { Mass loss } \\
(\%)\end{array}$ & $\mathrm{T}_{\max }\left({ }^{\circ} \mathrm{C}\right)$ & Mass (\%) \\
\hline RH & $58.0 \pm 0.6$ & $2.77 \pm 0.04$ & $70.3 \pm 0.9$ & $252.3 \pm 1.3$ & $55.0 \pm 0.4$ & $345.4 \pm 0.8$ & $32.6 \pm 0.2$ \\
\hline RH-A & $63.4 \pm 0.1$ & $3.01 \pm 0.05$ & $67.2 \pm 2.1$ & $274.6 \pm 0.5$ & $63.6 \pm 1.3$ & $330.8 \pm 0.1$ & $23.8 \pm 1.7$ \\
\hline RH-A-B & $71.0 \pm 0.2$ & $2.86 \pm 0.09$ & $60.5 \pm 4.2$ & $303.0 \pm 0.3$ & $74.7 \pm 0.2$ & $346.8 \pm 0.1$ & $15.9 \pm 0.2$ \\
\hline CNC-A & $80.5 \pm 0.3$ & $2.11 \pm 0.04$ & $60.0 \pm 2.0$ & $207.5 \pm 0.3$ & $87.5 \pm 3.0$ & $265 \pm 1.0 /$ & $10.0 \pm 2.9$ \\
& & & & & & $349 \pm 1.0 /$ & \\
& & & & & & $418 \pm 1.0$ & \\
\hline RH-H & 60.1 & $2.13 \pm 0.10$ & $59.3 \pm 0.4$ & $318.3 \pm 0.3$ & $59.9 \pm 0.3$ & $363.8 \pm 0.5$ & $28.9 \pm 0.4$ \\
\hline RH-H-B & $67.7 \pm 2.4$ & $2.63 \pm 0.01$ & $55.0 \pm 0.6$ & $301.8 \pm 1.3$ & $63.5 \pm 0.4$ & $344.4 \pm 0.1$ & $27.9 \pm 0.6$ \\
\hline CNC-H & $74.0 \pm 1$ & $2.03 \pm 0.50$ & $54.9 \pm 0.5$ & $189 \pm 2.4$ & $49.0 \pm 2.4$ & $226.0 \pm 2.0 /$ & $48.8 \pm 2.7$ \\
& & & & & & $265.9 \pm 2.0 /$ & \\
& & & & & & $350.0 \pm 1.0$ & \\
\hline
\end{tabular}

Finally, thermogravimetric analyses were carried out to determine the thermal stability of the rice husk fibres and the different samples obtained along both processes. Figure 4C shows the mass loss (TG) and derivative (DTG) curves obtained for the different samples, where two main mass loss steps at higher and lower temperatures are distinguished, excluding the CNC samples. The thermogravimetric parameters for each mass loss steps, including the mass loss and the onset and maximum decomposition temperatures are presented in Table 4. The mass loss step $(<3 \%)$ at lower temperature $\left(25-150^{\circ} \mathrm{C}\right)$ is attributed to the loss of the absorbed water, whereas the main step ( $>55 \%)$ at temperatures between $180^{\circ} \mathrm{C}$ and $550^{\circ} \mathrm{C}$ is assigned to the thermal degradation of the cellulose, hemicellulose and lignin components. The TGA 
results also validated the extraction of the amorphous non-cellulosic components during the alkaline and bleaching treatments, since the main degradation peak showed smaller shoulders at lower temperatures (between $250^{\circ} \mathrm{C}-300^{\circ} \mathrm{C}$ ), attributed to the hemicellulose and lignin fractions on the DTG curve. These amorphous components have a lower degradation temperatures compared to cellulose and their progressive removal resulted in a higher thermal stability of the insoluble fractions. However, the sulphuric acid hydrolysis resulted in more thermosensitive CNCs, due to the surface sulfation. ${ }^{10}$ The CNCs obtained from the alkali treatment (CNC-A) showed higher thermal stability than those from the hydrothermal process (CNC-H), which could be related with their higher crystallinity.

The morphological and thermal properties of the CNCs influence their performance and their potential application as reinforcement in composite materials. The morphology of the CNCs depends not only on the source of the original lignocellulose feedstock, but also largely on the isolation process. The physico-chemical properties of the isolated CNCs from rice husk using both alkali and hydrothermal processes are here compared and discussed in terms of aspect ratio (1/D), crystallinity and thermal stability (Table 5). The aspect ratio for both isolated CNCs are higher than 10, therefore these nanoparticles have the potential to behave as good reinforcing agents in composites. ${ }^{40}$ The aspect ratio distribution of the alkali treated CNC was broader than for the CNC-H. The averaged aspect ratio for both $\mathrm{CNC}-\mathrm{A}$ and $\mathrm{CNC}-\mathrm{H}$ was similar (47 and 50, respectively) and higher than previous aspect ratio values of CNCs isolated from rice husk (15). ${ }^{10,36}$ Therefore, the rice husk CNCs obtained by both processes can potentially provide very high reinforcing effects as deduced from their high aspect ratio, enhancing mechanical properties of composite materials when used as fillers at low loadings. 
Table 5. Physico-chemical properties of the isolated cellulose nanocrystals from rice husk the alkali treatment process $(\mathrm{CNC}-\mathrm{A})$ and the hydrothermal process $(\mathrm{CNC}-\mathrm{H})$.

\begin{tabular}{lll}
\cline { 2 - 3 } & CNC-A & CNC-H \\
\hline Purity & $96 \pm 5$ & $56 \pm 6$ \\
Aspect ratio (1/D) & $14-162$ & $50-178$ \\
CrI $(\%)$ & $80.5 \pm 0.3$ & $74 \pm 1.0$ \\
$\mathbf{T}_{\text {onset }}\left({ }^{\circ} \mathbf{C}\right)$ & $207.5 \pm 0.3$ & $189 \pm 2.4$ \\
\hline
\end{tabular}

The centrifugation step for the purification of $\mathrm{CNC}-\mathrm{H}$ after the hydrolytic treatment also retained part of the inorganic silica particles, thus contributing to the higher ash content and the reduced purity of the $\mathrm{CNC}-\mathrm{H}$ fraction compared to the $\mathrm{CNC}-\mathrm{A}$ from the alkaline process (Table 5). However, further efforts should be devoted to the selective separation of the CNC and the inorganic silica particles in other applications where high purities are required. When comparing the $\mathrm{CNCs}$ produced by the alkaline $(\mathrm{CNC}-\mathrm{A})$ and the hydrothermal treatments (CNC-H), the latter shows lower crystallinity compared to those obtained by the traditional alkaline process. This may indicate that the presence of silica hinders the acid hydrolysis of the amorphous parts of the cellulose, resulting in $\mathrm{CNC}-\mathrm{H}$ samples with higher amorphous regions, which correlates well with the observed higher lengths. In addition to this, the onset temperature for the nanocrystals obtained from the alkaline process is higher than the equivalent ones from the hydrothermal process, which is as well related to the crystallinity and morphology of the crystals. A consideration for the proposed process would be to introduce an alkaline step after the initial subcritical water extraction. This additional step would enable the isolation of the bioactive hemicelluloses during the subcritical water process and provide a cleaner cellulose fraction with milder bleaching conditions. However, the silica particles would be dissolved under alkaline conditions and would be therefore not recovered. The implementation of these alternatives at a larger scale should consider holistically the value of the recovered fractions and the technical sustainability of the process. 


\section{Conclusions}

560 A cascade process for the isolation of arabinoxylans and cellulose nanocrystals (CNC) from 561 rice husk, combining subcritical water extraction (SWE), bleaching and acid hydrolysis, is 562 here monitored from the macro- to the nano dimensions and compared to the traditional 563 alkaline process. The hydrothermal and alkaline processes result in arabinoxylan populations 564 with distinct molecular structures in terms of substitutions and molar mass. The hydrothermal 565 process enables the extraction of arabinoxylans with antioxidant and antibacterial activity, which is attributed to the preservation of the phenolic acid moieties (mainly ferulic acid) that are lost during the alkaline process. The hydrothermal process can be envisaged as a suitable pre-treatment for the isolation of $\mathrm{CNCs}$ and the recovery of silica particles after the subsequent bleaching and acid hydrolysis steps. The resulting CNCs from the hydrothermal process have suitable morphology, aspect ratio, crystallinity, and thermal stability, although with lower purities than the alternative alkaline process due to the co-extraction of silica particles. However, the synergistic potential of using both CNCs and silica particles as

573 reinforcing agents in biocomposite applications remains an exciting and unexplored 574 possibility for this fraction. This cascade process constitutes an eco-friendly strategy towards 575 the integral valorization of rice husk into multiple valuable components, which can be 576 replicated in other important agricultural by-products.

\section{Acknowledgements}

579 The authors thank the Ministerio de Economía y Competitividad (Spain) for the financial 580 support provided through Project AGL2016-76699-R. Author Raquel Requena thanks the 581 Ministry of Education, Culture and Sport (Spain) for the FPU (FPU13/03444) Grant. This 582 research work was also financed with a Short Term Scientific Mission of the COST Action 583 FP1405. 
1. Muthayya, S.; Sugimoto, J. D.; Montgomery, S.; Maberly, G. F., An overview of global rice production, supply, trade, and consumption. Annals of the New York Academy of Sciences 2014, 1324 (1), 7-14.

2. Battegazzore, D.; Bocchini, S.; Alongi, J.; Frache, A.; Marino, F., Cellulose extracted from rice husk as filler for poly(lactic acid): preparation and characterization. Cellulose 2014, 21 (3), 1813-1821.

3. Ebrahimi, M.; Villaflores, O. B.; Ordono, E. E.; Caparanga, A. R., Effects of acidified aqueous glycerol and glycerol carbonate pretreatment of rice husk on the enzymatic digestibility, structural characteristics, and bioethanol production. Bioresource Technology 2017, 228, 264-271.

4. Tsai, W. T.; Lee, M. K.; Chang, Y. M., Fast pyrolysis of rice husk: Product yields and compositions. Bioresource Technology 2007, 98 (1), 22-28.

5. Prasad, R.; Pandey, M., Rice Husk Ash as a Renewable Source for the Production of Value Added Silica Gel and its Application: An Overview. 2012 2012, 25.

6. Yussuf, A. A.; Massoumi, I.; Hassan, A., Comparison of Polylactic Acid/Kenaf and Polylactic Acid/Rise Husk Composites: The Influence of the Natural Fibers on the Mechanical, Thermal and Biodegradability Properties. Journal of Polymers and the Environment 2010, 18 (3), 422-429.

7. Wu, C.-S., Preparation and Characterization of Polyhydroxyalkanoate BioplasticBased Green Renewable Composites from Rice Husk. Journal of Polymers and the Environment 2014, 22 (3), 384-392.

8. Zhao, Q.; Tao, J.; Yam, R. C. M.; Mok, A. C. K.; Li, R. K. Y.; Song, C., Biodegradation behavior of polycaprolactone/rice husk ecocomposites in simulated soil medium. Polymer Degradation and Stability 2008, 93 (8), 1571-1576.

9. Gao, Y.; Guo, X.; Liu, Y.; Fang, Z.; Zhang, M.; Zhang, R.; You, L.; Li, T.; Liu, R. H., A full utilization of rice husk to evaluate phytochemical bioactivities and prepare cellulose nanocrystals. Scientific Reports 2018, 8 (1), 10482.

10. Johar, N.; Ahmad, I.; Dufresne, A., Extraction, preparation and characterization of cellulose fibres and nanocrystals from rice husk. Industrial Crops and Products 2012, 37 (1), 93-99.

11. Grishkewich, N.; Mohammed, N.; Tang, J.; Tam, K. C., Recent advances in the application of cellulose nanocrystals. Current Opinion in Colloid \& Interface Science 2017, $29,32-45$.

12. Brinchi, L.; Cotana, F.; Fortunati, E.; Kenny, J. M., Production of nanocrystalline cellulose from lignocellulosic biomass: Technology and applications. Carbohydrate Polymers 2013, 94 (1), 154-169.

13. Ruthes, A. C.; Martinez-Abad, A.; Tan, H.-T.; Bulone, V.; Vilaplana, F., Sequential fractionation of feruloylated hemicelluloses and oligosaccharides from wheat bran using subcritical water and xylanolytic enzymes. Green Chemistry 2017, 19 (8), 1919-1931.

14. Egüés, I.; Stepan, A. M.; Eceiza, A.; Toriz, G.; Gatenholm, P.; Labidi, J., Corncob arabinoxylan for new materials. Carbohydrate Polymers 2014, 102, 12-20.

15. Zhang, Z.; Smith, C.; Li, W., Extraction and modification technology of arabinoxylans from cereal by-products: A critical review. Food Research International 2014, 65, 423-436.

16. Hanim, S. S.; Norsyabilah, R.; Suhaila, M. H. N.; Noraishah, A.; Kartina, A. K. S., Effects of Temperature, Time and Pressure on the Hemicelluloses Yield Extracted Using Subcritical Water Extraction. Procedia Engineering 2012, 42, 562-565.

17. Kilpeläinen, P. O.; Hautala, S. S.; Byman, O. O.; Tanner, L. J.; Korpinen, R. I.; Lillandt, M. K. J.; Pranovich, A. V.; Kitunen, V. H.; Willför, S. M.; Ilvesniemi, H. S., 
Pressurized hot water flow-through extraction system scale up from the laboratory to the pilot scale. Green Chemistry 2014, 16 (6), 3186-3194.

18. Moriana, R.; Vilaplana, F.; Ek, M., Cellulose Nanocrystals from Forest Residues as Reinforcing Agents for Composites: A Study from Macro- to Nano-Dimensions. Carbohydrate Polymers 2016, 139, 139-149.

19. Le Normand, M.; Moriana, R.; Ek, M., Isolation and characterization of cellulose nanocrystals from spruce bark in a biorefinery perspective. Carbohydrate Polymers 2014, $111,979-987$.

20. McKee, L. S.; Sunner, H.; Anasontzis, G. E.; Toriz, G.; Gatenholm, P.; Bulone, V.; Vilaplana, F.; Olsson, L., A GH115 a-glucuronidase from Schizophyllum commune contributes to the synergistic enzymatic deconstruction of softwood glucuronoarabinoxylan. Biotechnology for Biofuels 2016, 9 (1), 1-13.

21. Comino, P.; Collins, H.; Lahnstein, J.; Beahan, C.; Gidley, M. J., Characterization of soluble and insoluble cell wall fractions from rye, wheat and hull-less barley endosperm flours. Food Hydrocolloids 2014, 41, 219-226.

22. Ciucanu, I.; Kerek, F., A simple and rapid method for the permethylation of carbohydrates. Carbohydrate Research 1984, 131 (2), 209-217.

23. Morais de Carvalho, D.; Martínez-Abad, A.; Evtuguin, D. V.; Colodette, J. L.; Lindström, M. E.; Vilaplana, F.; Sevastyanova, O., Isolation and characterization of acetylated glucuronoarabinoxylan from sugarcane bagasse and straw. Carbohydrate Polymers 2017, 156, 223-234.

24. Brand-Williams, W.; Cuvelier, M. E.; Berset, C., Use of a free radical method to evaluate antioxidant activity. LWT - Food Science and Technology 1995, 28 (1), 25-30.

25. Talón, E.; Trifkovic, K. T.; Nedovic, V. A.; Bugarski, B. M.; Vargas, M.; Chiralt, A.; González-Martínez, C., Antioxidant edible films based on chitosan and starch containing polyphenols from thyme extracts. Carbohydrate Polymers 2017, 157, 1153-1161.

26. TAPPI, Acid insoluble lignin in wood and pulp. Technical Association of Pulp and Paper Industry: 2006; Vol. T 222 om-06.

27. Sluiter, A.; Ruiz, R.; Scarlata, C.; Sluiter, J.; Templeton, D., Determination of extractives in biomass. Laboratory analytical procedure (LAP) 2008.

28. Gordobil, O.; Moriana, R.; Zhang, L.; Labidi, J.; Sevastyanova, O., Assesment of technical lignins for uses in biofuels and biomaterials: Structure-related properties, proximate analysis and chemical modification. Industrial Crops and Products 2016, 83, 155-165.

29. Saeman, J. F.; Moore, W. E.; Mitchell, R. L.; Millett, M. A., Techniques for the determination of pulp constituents by quantitiative paper chromatography. Tappi Journal 1954, 37 (8), 336-343.

30. Segal, L.; Creely, J. J.; Martin, A. E.; Conrad, C. M., An Empirical Method for Estimating the Degree of Crystallinity of Native Cellulose Using the X-Ray Diffractometer. Textile Research Journal 1959, 29 (10), 786-794.

31. Sun, R.; Sun, X. F.; Wang, S. Q.; Zhu, W.; Wang, X. Y., Ester and ether linkages between hydroxycinnamic acids and lignins from wheat, rice, rye, and barley straws, maize stems, and fast-growing poplar wood. Industrial Crops and Products 2002, 15 (3), 179-188.

32. Misaki, A., Structure of Hemicellulose Isolated from Rice Endosperm Cell Wall : Mode of Linkages and Sequences in Xyloglucan, $\beta$-Glucan and Arabinoxylan AU - Shibuya, Naoto. Agricultural and Biological Chemistry 1978, 42 (12), 2267-2274.

33. Martínez-Abad, A.; Giummarella, N.; Lawoko, M.; Vilaplana, F., Differences in extractability under subcritical water reveal interconnected hemicellulose and lignin recalcitrance in birch hardwoods. Green Chemistry 2018, 20 (11), 2534-2546. 
34. Holmbom, B.; Willför, S., Two-Stage Hot-Water Extraction of Galactoglucomannans from Spruce Wood AU - Pranovich, Andrey. Journal of Wood Chemistry and Technology 2016, 36 (2), 140-156.

35. Von Schoultz, S. Method for extracting biomass. 2014.

36. Collazo-Bigliardi, S.; Ortega-Toro, R.; Chiralt Boix, A., Isolation and characterisation of microcrystalline cellulose and cellulose nanocrystals from coffee husk and comparative study with rice husk. Carbohydrate Polymers 2018, 191, 205-215.

37. Hubbe, M. A.; Rojas, O. J.; Lucia, L. A.; Sain, M., CELLULOSIC NANOCOMPOSITES: A REVIEW. 2008; Vol. 3.

38. Chauve, G.; Fraschini, C.; Jean, B., Separation of Cellulose Nanocrystals. In Handbook of Green Materials, Oksman, K.; Mathew, A. P.; Bismark, A.; Rojas, O. J.; Sain, M., Eds. World Scientific Publishing Co., 2013; pp 73-87.

39. Prasad Reddy, J.; Rhim, J.-W., Isolation and characterization of cellulose nanocrystals from garlic skin. Materials Letters 2014, 129, 20-23.

40. Silvério, H. A.; Flauzino Neto, W. P.; Dantas, N. O.; Pasquini, D., Extraction and characterization of cellulose nanocrystals from corncob for application as reinforcing agent in nanocomposites. Industrial Crops and Products 2013, 44, 427-436. 